\title{
Hysteretic Behavior of H-Shaped Honeycombed Steel Web Composite Columns with Rectangular Concrete-Filled Steel Tube Flanges
}

\author{
Jing Ji, ${ }^{1,2}$ Yubo Lin $\mathbb{D}^{1},{ }^{1}$ Liangqin Jiang $\mathbb{D}^{1,2}$ Wen Li, ${ }^{1}$ Hongguo Ren ${ }^{1},{ }^{3}$ Ruili Wang, \\ Zihao Wang $\mathbb{D}^{3}{ }^{3}$ MaoMao Yang, ${ }^{1}$ and Chenyu Yu $\mathbb{D}^{1}$ \\ ${ }^{1}$ College of Civil and Architectural Engineering, Northeast Petroleum University, \\ Heilongjiang Key Laboratory of Disaster Prevention, Mitigation and Protection Engineering, No. 99 Xuefu Road, Longfeng, \\ Daqing 163318, China \\ ${ }^{2}$ Key Laboratory of Earthquake Engineering and Engineering Vibration, Institute of Engineering Mechanics, \\ China Earthquake Administration, No. 29 Xuefu Road, Nangang, Harbin 150000, China \\ ${ }^{3}$ Handan Key Laboratory of Building Physical Environment and Regional Building Protection Technology, \\ School of Architecture and Art, Hebei University of Engineering, No. 19 Taiji Road, \\ Handan Economic and Technological Development District, Handan 056038, China \\ ${ }^{4}$ School of Management Engineering and Business, Hebei University of Engineering, No. 199 Guangming South Road, Hanshan, \\ Handan 056038, China
}

Correspondence should be addressed to Hongguo Ren; renhongguo771126@163.com and Zihao Wang; wangzihao20211031@ 163.com

Received 7 November 2021; Accepted 27 December 2021; Published 1 February 2022

Academic Editor: Lingkun Chen

Copyright (C) 2022 Jing Ji et al. This is an open access article distributed under the Creative Commons Attribution License, which permits unrestricted use, distribution, and reproduction in any medium, provided the original work is properly cited.

\begin{abstract}
This study aims to investigate the hysteretic behavior of $\mathrm{H}$-shaped honeycombed steel web composite columns with rectangular concrete-filled steel tube flanges (STHCCs). Taking the shear span ratio $\left(\lambda_{s}\right)$, axial compression ratio $(n)$, steel ratio of section $(\alpha)$, aspect ratio of section $(D / B)$, yield strength of steel tube $\left(f_{\text {yfk }}\right)$, and compressive strength of concrete $\left(f_{\text {ck }}\right)$ as the main parameters, we designed 22 full-scale STHCCs. By comparing the load-displacement curves between test and simulation, the rationality of finite element modeling method was verified. The quasi-static analysis of 22 specimens was carried out, and the influence regularity of different variables on the hysteretic behavior, skeleton curves, ductility, energy dissipation, resistance degradation, and stiffness degradation of STHCCs was obtained. The results show that the hysteresis curves of all the specimens show full shuttle shape and strong energy dissipation capacity. $\lambda_{s}, \alpha$, and $f_{\text {yfk }}$ have great influence on the bearing capacity of skeleton curves. With the increase of $\alpha$ and $f_{\mathrm{yfk}}$, the initial stiffness of the specimens gradually increases. The stiffness degradation rate of the specimens gradually slows down, and the energy dissipation coefficient gradually decreases by increasing $\lambda_{s}, \alpha$, and $f_{\text {yfk }}$, but energy dissipation capacity is still at a high level. The resistance degradation of specimens increases gradually by increasing $\lambda_{s}, \alpha, f_{\mathrm{yfk}}$, and $D / B$. The ductility of specimens gradually increases by increasing $n, \alpha$, and $f_{\mathrm{ck}}$. The maximum bulging deformation and maximum stress of specimens appear at the column foot. The trilinear skeleton curve model and restoring force model of STHCCs are established by statistical regression.
\end{abstract}

\section{Introduction}

STHCCs, short for H-shaped honeycombed steel web composite columns with rectangular concrete-filled steel tube flanges, are a kind of novel composite members formed by connecting two concrete-filled rectangular steel tube flanges with a honeycombed steel web. The core concrete can effectively prevent and delay the local buckling of the steel tube and the instability failure of the specimens; the steel tube also has certain restraint action on the concrete, which results in 
the core concrete under a state of triaxial compression; and the compressive strength and the ability to resist deformation of the core concrete can be significantly improved.

Since the twentieth century, a lot of research has been carried out regarding concrete-filled steel tube (CFST) columns and honeycombed columns at home and abroad. Sakino et al. [1] designed and fabricated 114 short CFST columns with different parameters of the shape of the steel tube, the tensile strength of the steel tube, the diameterthickness ratio of the steel tube, and the strength of the concrete, and a formula for the ultimate axial bearing capacity was proposed. The mechanical behavior of concretefilled double-layer circular steel tube columns was studied by Essopjee and Dundu [2]. The tests of 32 specimens subjected to axial compression were conducted, and the bearing capacity formula of concrete-filled double-layer circular steel tube columns was proposed. Anupriya et al. [3] carried out experimental research on honeycomb beams with stiffeners and without stiffeners, analyzed the failure mode of honeycomb beams under concentrated load, and also proposed a method for calculating the compressive strength of honeycomb beams webs after buckling. The nonlinear buckling analysis of 30 STHCCs with different parameters were carried out by Ji et al. [4]. According to the finite element (FE) simulation results, the formula for calculating the stability bearing capacity of STHCCs was derived. In order to investigate the axial compression behavior of short STHCCs with different parameters, an experimental study of 16 short STHCCs was designed and carried out by Ji et al. [5], and the calculation formula of the axial bearing capacity for this type of short column was established. In 2020, Ji et al. [6] investigated the eccentric compression performance of 17 STHCCs by ABAQUS software and derived the calculation formula of eccentric compression bearing capacity for STHCCs. Low-cycle repeated loading tests on CFST beamcolumn structures were conducted by Varma et al. [7], the FE model of the structure was established, and the reliability of the model was verified, which provided a basis for the calculation of the bearing capacity of CFST structures. Gajalakshmi and Helena [8] took the diameter-thickness ratio of steel tube as a variable to conduct low-cycle repeated loading tests on four circular CFST columns, analyzed the variations of hysteretic curves for CFST columns under different loading levels, and proposed a simplified damage accumulation equation of CFST columns. Low cyclic loading tests on recycled CFST columns and ordinary CFST columns were carried out by Chen et al. [9] and Tang et al. [10]. The influence of axial compression ratio, steel tube strength, steel tube thickness, and other parameters on the seismic behavior of CFST columns was discussed, and a fitting formula for skeleton curve based on Boltzmann mathematical model was proposed. The seismic capacity of 16 ultralarge high strength concrete-filled circular steel tube (HCFTST) columns under cyclic loading was analyzed by Wang et al. [11], and a strength model to predict the bending moment bearing capacity was proposed. Five specimens of multicavity CFST specially shaped columns were designed and fabricated by Yin et al. [12]. Through the combination of quasi-static and numerical simulation, the failure mode, hysteresis characteristic, stiffness degradation, ductility, and energy dissipation capacity of each specimen were obtained, and the effect of various parameters on the mechanism of force was explained. The calculation method of characteristic points' values for skeleton curve for solid-web steel reinforced concrete T-shaped column was proposed by Liu et al. [13], and the restoring force model was established, which provided the basis for elastic-plastic seismic response analysis of this type of structure.

The research on STHCCs is mainly aimed at axial compression and stability, and few studies have been done on the hysteretic behavior of this kind of composite columns. Based on the research results of axial compression test of STHCCs, the quasi-static analysis of 22 STHCCs under low cyclic loading is further carried out by ABAQUS software. The influence of different parameters on the hysteretic behavior, skeleton curve, ductility, energy dissipation capacity, resistance attenuation, and stiffness degradation of STHCCs is investigated. The hysteretic behavior and failure form of STHCCs are obtained, and the restoring force model of such columns is established.

\section{Specimen Overview}

Taking the shear span ratio $\left(\lambda_{s}\right)$, axial compression ratio $(n)$, steel ratio of section $(\alpha)$, aspect ratio of section $(D / B)$, yield strength of steel tube $\left(f_{\text {yfk }}\right)$, and compressive strength of concrete $\left(f_{\mathrm{ck}}\right)$ as the main parameters, we design 22 full-scale STHCCs. The schematic diagram and specific parameters of the specimens are shown in Figure 1 and Table 1. Considering the confinement effect of steel tube on concrete, pitch-height ratio, hole-height ratio, and slenderness ratio, the nominal axial compression ratio $(n)$ [14] of the specimens is calculated as follows:

$$
n=\frac{N}{N_{u}}=\frac{N}{\left[\left(d / h_{w}\right)^{-0.39}+\left(s / h_{w}\right)^{0.717}+\xi^{0.178}+\bar{\lambda}_{o y}{ }^{-0.227}-1.284\right] \times \varphi \sum A_{s c i} \times f_{s c}}
$$

where $\bar{\lambda}_{\text {oy }}$ refers to the conversion slenderness ratio of the columns, $f_{\mathrm{sc}}$ refers to the equivalent strength of CFST section, $A_{s c i}$ denotes the section area of single-limb CFST, $\mathrm{Nu}$ denotes the design value of axial compression bearing capacity of the columns, $\varphi$ represents the stability coefficient of CFST axial compression specimens, and $s / h_{w}$ and $d / h_{w}$ represent the pitch-height ratio and the hole-height ratio, respectively. 


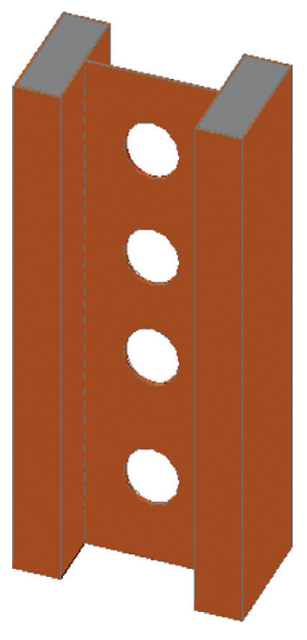

(a)

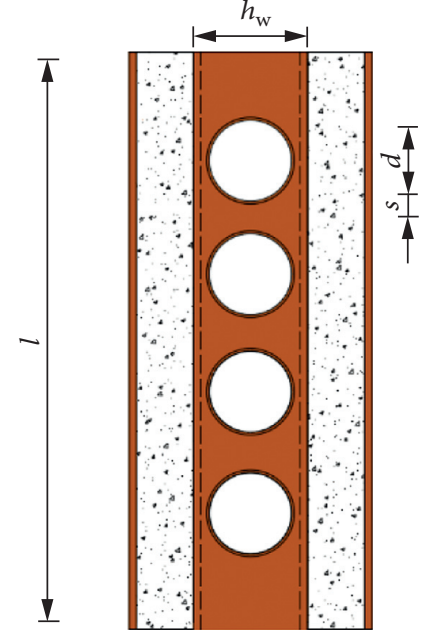

(b)

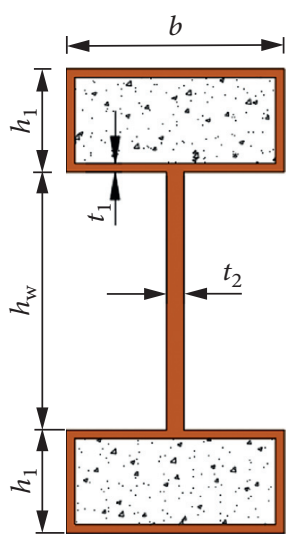

(c)

FIgURE 1: The three-dimensional model of STHCCs. (a) Three-dimensional model. (b) Longitudinal section of STHCCs. (c) Cross section of STHCCs.

TABLE 1: Specific parameters of 22 STHCC specimens.

\begin{tabular}{|c|c|c|c|c|c|c|c|c|}
\hline Specimens & $h_{1} \times b \times h_{w} \times t_{1} \times t_{2}(\mathrm{~mm})$ & $L(\mathrm{~mm})$ & $D / B$ & $\lambda_{\mathrm{s}}$ & $n$ & $\alpha$ & $f_{\mathrm{ck}}(\mathrm{MPa})$ & $f_{\mathrm{yfk}}(\mathrm{MPa})$ \\
\hline STHCC1 & $320 \times 500 \times 400 \times 8 \times 10$ & 2160 & 2.08 & 2.08 & 0.4 & 0.044 & 40 & 235 \\
\hline STHCC2 & $320 \times 500 \times 400 \times 8 \times 10$ & 2550 & 2.08 & 2.45 & 0.4 & 0.044 & 40 & 235 \\
\hline STHCC3 & $320 \times 500 \times 400 \times 8 \times 10$ & 2750 & 2.08 & 2.64 & 0.4 & 0.044 & 40 & 235 \\
\hline STHCC4 & $320 \times 500 \times 400 \times 8 \times 10$ & 3460 & 2.08 & 3.33 & 0.4 & 0.044 & 40 & 235 \\
\hline STHCC5 & $320 \times 500 \times 400 \times 8 \times 10$ & 3460 & 2.08 & 3.33 & 0.1 & 0.044 & 40 & 235 \\
\hline STHCC6 & $320 \times 500 \times 400 \times 8 \times 10$ & 3460 & 2.08 & 3.33 & 0.2 & 0.044 & 40 & 235 \\
\hline STHCC7 & $320 \times 500 \times 400 \times 8 \times 10$ & 3460 & 2.08 & 3.33 & 0.3 & 0.044 & 40 & 235 \\
\hline STHCC8 & $320 \times 500 \times 400 \times 8 \times 10$ & 3460 & 2.08 & 3.33 & 0.4 & 0.044 & 30 & 235 \\
\hline STHCC9 & $320 \times 500 \times 400 \times 8 \times 10$ & 3460 & 2.08 & 3.33 & 0.4 & 0.044 & 50 & 235 \\
\hline STHCC10 & $320 \times 500 \times 400 \times 8 \times 10$ & 3460 & 2.08 & 3.33 & 0.4 & 0.044 & 60 & 235 \\
\hline STHCC11 & $320 \times 500 \times 400 \times 4 \times 10$ & 3460 & 2.08 & 3.33 & 0.4 & 0.021 & 40 & 235 \\
\hline STHCC12 & $320 \times 500 \times 400 \times 6 \times 10$ & 3460 & 2.08 & 3.33 & 0.4 & 0.032 & 40 & 235 \\
\hline STHCC13 & $320 \times 500 \times 400 \times 10 \times 10$ & 3460 & 2.08 & 3.33 & 0.4 & 0.056 & 40 & 235 \\
\hline STHCC14 & $320 \times 500 \times 400 \times 8 \times 10$ & 3460 & 2.08 & 3.33 & 0.4 & 0.044 & 40 & 345 \\
\hline STHCC15 & $320 \times 500 \times 400 \times 8 \times 10$ & 3460 & 2.08 & 3.33 & 0.4 & 0.044 & 40 & 390 \\
\hline STHCC16 & $320 \times 500 \times 400 \times 8 \times 10$ & 3460 & 2.08 & 3.33 & 0.4 & 0.044 & 40 & 420 \\
\hline STHCC17 & $320 \times 550 \times 400 \times 8 \times 10$ & 3460 & 1.89 & 3.33 & 0.4 & 0.042 & 40 & 235 \\
\hline STHCC18 & $320 \times 600 \times 400 \times 8 \times 10$ & 3460 & 1.73 & 3.33 & 0.4 & 0.041 & 40 & 235 \\
\hline STHCC19 & $320 \times 650 \times 400 \times 8 \times 10$ & 3460 & 1.60 & 3.33 & 0.4 & 0.040 & 40 & 235 \\
\hline STHCC20 & $280 \times 500 \times 400 \times 8 \times 10$ & 3460 & 1.92 & 3.33 & 0.4 & 0.048 & 40 & 235 \\
\hline STHCC21 & $400 \times 500 \times 400 \times 8 \times 10$ & 3460 & 2.40 & 3.33 & 0.4 & 0.031 & 40 & 235 \\
\hline STHCC22 & $480 \times 500 \times 400 \times 8 \times 10$ & 3460 & 2.72 & 3.33 & 0.4 & 0.034 & 40 & 235 \\
\hline
\end{tabular}

Note. $h_{w}, h_{1}, b, t_{1}$, and $t_{2}$ denote the web width, flange steel tubes height, flange steel tubes width, flange steel tubes thickness, and web thickness, respectively. $\lambda_{s}=l /\left(2 h_{1}+h_{\mathrm{w}}\right), D / B=\left(2 h_{1}+h_{\mathrm{w}}\right) / b, \alpha=A_{s} / A_{c} . A_{s}$ and $A_{c}$ represent the area of flange steel tube and concrete, respectively.

\section{Finite Element Model}

\subsection{Constitutive Model for Materials}

3.1.1. Constitutive Model for Steel. According to the metal plasticity theory, the stress-strain curves of steel are generally determined by the tensile test of standard specimens. Here, the ideal bilinear elastoplastic constitutive model (CM) is adopted as CM of steel.
3.1.2. Constitutive Model for Concrete. Mander et al. [15], Teng et al. [16], Han [17], and Pagoulatou et al. [18] have successively given the CM of confined concrete; the CM of unconfined concrete has been given in Code for Design of Concrete Structures (GB50010-2010) by China [19]; and the comparison between them is shown in Figure 2. Through comparative analysis, the CM of confined concrete proposed by Han et al. [17] is adopted as CM of concrete. It is known 


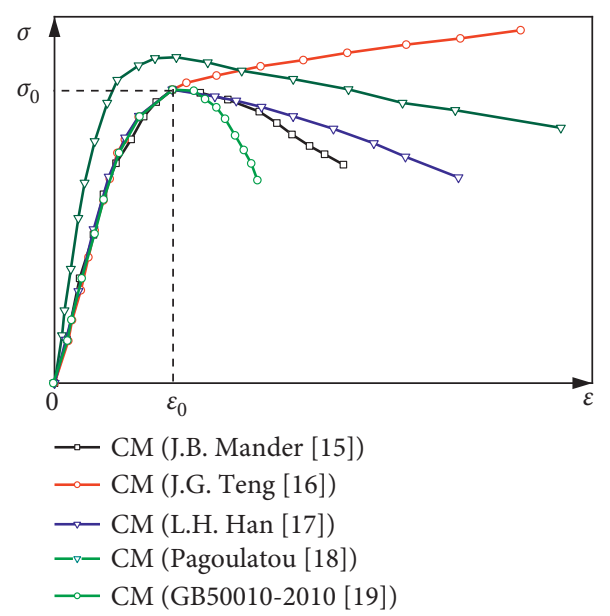

Figure 2: Typical constitutive models for concrete.

that concrete is anisotropic material with uneven internal structure and complex mechanical behavior, so the influence of plastic damage on concrete is considered during the FE modeling process.

3.2. Modeling Process and Boundary Conditions. The threedimensional solid element with eight nodes (C3D8R) was adopted to simulate steel tubes, concrete, and steel webs, and the FE models of STHCCs were established by ABAQUS software [20], as shown in Figure 3. The contact interaction between steel tube and concrete was set as normal contact and bond slip contact in tangential direction, thus shear stress can be transmitted between steel tube and concrete [21]. The friction coefficient $(\mu)$ was set as 0.3 [22].

A reference point was set at the center of the upper surface of STHCCs as shown in Figure 3, and the reference point was coupled with the corresponding specimen surfaces, which could ensure that the stress on the specimen surface was uniform in the process of axial compression, and could avoid the bias of the members as well. The displacement in $X, Y$ directions and the rotation in three directions of the reference point were restricted $(U x=U y=U R x=U R y=U R z=0)$, while the bottom of STHCCs was completely fixed. In order to ensure the quality of meshing and the accuracy of calculation, $80 \mathrm{~mm}$ was taken as the mesh size of FEM, and the mesh shape was mainly hexahedron.

\section{Experimental Verification of FE Models}

In order to verify the rationality of the above-mentioned modeling method, numerical simulation analysis on 14 specimens selected from [5] was carried out, and the specific parameters of the 14 specimens are listed in Table 2. The load-displacement curves of specimens obtained by simulation analysis are shown in Figure 4. Compared with the existing test curves, the load-displacement curves obtained by numerical simulation were in good agreement with the test results. The simulation results of the axial compression bearing capacity $\left(N_{u}^{S}\right)$ of the specimens were extracted correspondingly and compared with the existing test results
$\left(N_{u}^{T}\right)$ subsequently, and the maximum error was $5.58 \%$, as shown in Figure 5. The error was within a reasonable range, which indicated that the modeling method was applicable to such composite columns.

\section{Loading Procedure}

In the process of quasi-static analysis, the axial load $(N)$ is applied firstly to the top of the columns, then a force-displacement hybrid control program is used for lateral loading, and the loading procedure involved a force control step and a displacement control step as shown in Figure 6. In the force control stage, the increment of lateral load $(P)$ was $\pm 1 / 3$ times the yielding load $\left(P_{y}\right)$. The loading procedure was changed into the displacement control stage, and the increment of displacement was 0.4 times the peak displacement $\left(\Delta_{m}\right)$. Each displacement load step was repeated twice. When the lateral load of the specimens dropped below $85 \%$ of the peak load, the specimens were regarded as failure [23].

\section{Parameter Analysis}

6.1. Hysteresis Curves. The hysteresis curves of 22 STHCCs under low cyclic loading can be obtained by FE analysis as shown in Figure 7. The elasticity, elastic-plastic, plastic, ultimate bearing capacity, energy dissipation capacity, and ductility of the specimens can be reflected from the hysteresis curves [24]. It is indicated in Figure 7 that the hysteretic curves of all the specimens are relatively full, and there is no obvious pinching phenomenon from the early stage to the late stage. $\alpha$ has a great influence on the hysteresis curves of STHCC specimens; with the increase of $\alpha$, the hysteresis curve gradually becomes fuller, and the ultimate displacement of the specimens gradually increases. After reaching the peak load, the decrease of the bearing capacity of the specimens gradually slows down, and the ductility becomes better.

6.2. Skeleton Curves. The skeleton curves can intuitively reflect the force condition of STHCC specimens during the whole process of quasi-static simulation analysis, and the 


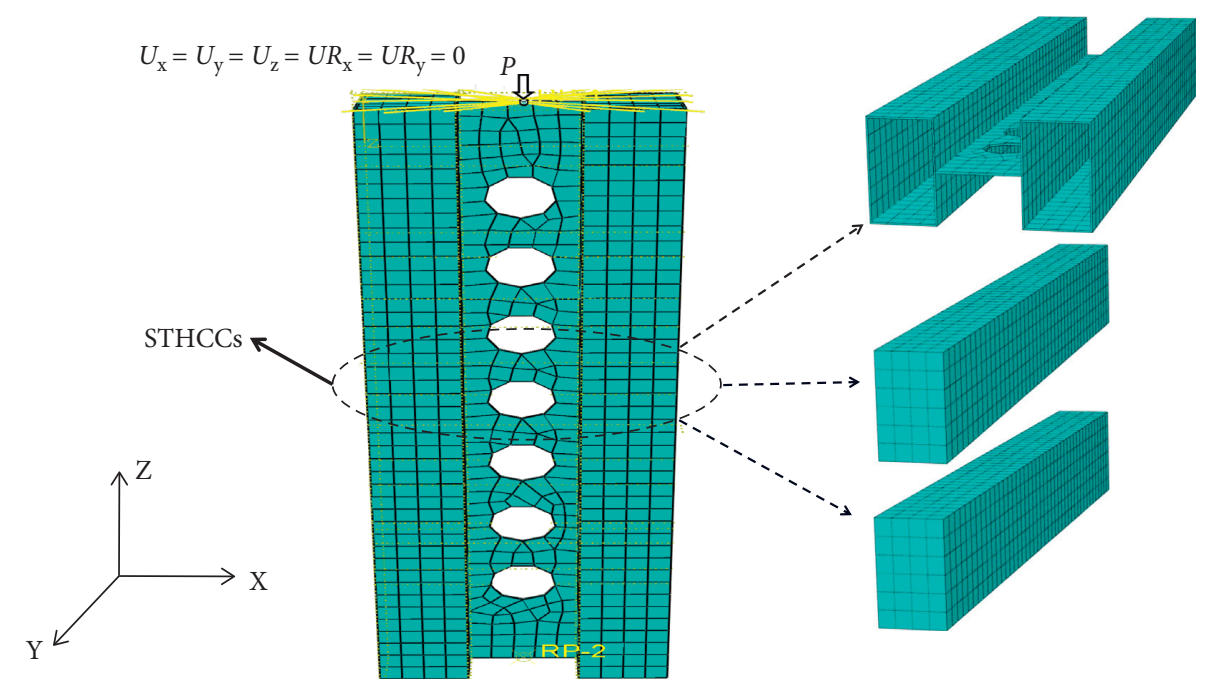

Figure 3: The FE model of STHCCs.

TABle 2: Comparison of simulation and test value subjected to axial compression.

\begin{tabular}{lcccccccccc}
\hline Specimens & $h_{1} \times b \times h_{w} \times t_{1} \times t_{2}(\mathrm{~mm})$ & $L(\mathrm{~mm})$ & $\lambda$ & $f_{\mathrm{yf}}(\mathrm{MPa})$ & $f_{\mathrm{yw}}(\mathrm{MPa})$ & $\xi$ & $f_{\mathrm{cu}}(\mathrm{MPa})$ & $N_{u}^{T}(\mathrm{kN})$ & $N_{u}^{S}(\mathrm{kN})$ & $\left|N_{u}^{T}-N_{u}^{S}\right| / N_{u}^{T}(\%)$ \\
\hline STHCC1 & $50 \times 100 \times 100 \times 1.7 \times 06$ & 370 & 12.82 & 269 & 321 & 0.60 & 49.50 & 741.21 & 736.94 & 0.58 \\
STHCC2 & $50 \times 100 \times 100 \times 2.3 \times 06$ & 370 & 12.82 & 282 & 321 & 0.88 & 49.50 & 864.59 & 912.83 & 5.58 \\
STHCC3 & $50 \times 100 \times 100 \times 3.8 \times 06$ & 370 & 12.82 & 286 & 321 & 1.60 & 49.50 & 1182.15 & 1184.33 \\
STHCC4 & $50 \times 100 \times 100 \times 2.3 \times 06$ & 370 & 12.82 & 282 & 321 & 0.82 & 53.17 & 1067.75 & 1037.13 & 1.20 \\
STHCC5 & $50 \times 100 \times 100 \times 2.3 \times 06$ & 370 & 12.82 & 282 & 321 & 0.66 & 65.60 & 1173.69 & 1168.35 & 0.45 \\
STHCC6 & $50 \times 100 \times 100 \times 2.3 \times 06$ & 370 & 12.82 & 282 & 321 & 0.78 & 55.69 & 1086.86 & 1053.54 & 3.08 \\
STHCC7 & $50 \times 100 \times 100 \times 1.7 \times 08$ & 370 & 12.82 & 269 & 325 & 0.60 & 49.50 & 763.17 & 781.58 & 2.41 \\
STHCC8 & $50 \times 100 \times 100 \times 1.7 \times 12$ & 370 & 12.82 & 269 & 331 & 0.60 & 49.50 & 798.26 & 786.84 & 1.43 \\
STHCC9 & $50 \times 100 \times 100 \times 2.3 \times 06$ & 270 & 9.35 & 282 & 321 & 0.88 & 49.50 & 948.52 & 957.48 & 0.94 \\
STHCC10 & $50 \times 100 \times 100 \times 2.3 \times 06$ & 470 & 16.28 & 282 & 321 & 0.88 & 49.50 & 841.31 & 863.90 & 2.44 \\
STHCC11 & $50 \times 100 \times 100 \times 1.7 \times 06$ & 270 & 9.35 & 269 & 321 & 0.60 & 49.50 & 781.37 & 761.63 & 1.53 \\
STHCC12 & $50 \times 100 \times 100 \times 1.7 \times 06$ & 470 & 16.28 & 269 & 321 & 0.60 & 49.50 & 716.92 & 733.36 & 2.29 \\
STHCC13 & $50 \times 100 \times 100 \times 3.8 \times 06$ & 270 & 9.35 & 286 & 321 & 1.60 & 49.50 & 1268.30 & 1273.31 \\
STHCC14 & $50 \times 100 \times 100 \times 3.8 \times 06$ & 470 & 16.28 & 286 & 321 & 1.60 & 49.50 & 1076.86 & 1088.53 & 0.40 \\
\hline
\end{tabular}

Note. $f_{\mathrm{y}}, f_{\mathrm{yw}}$, and $f_{\mathrm{cu}}$ denote the measured average value of the yield strength of the steel tube flange, the measured average value of the yield strength of the steel web, and the measured average value of the axial compressive strength of the cube concrete, respectively. $\lambda$ is the slenderness ratio, $\lambda=2 \sqrt{3} l / b, \xi$ represents the confinement effect coefficient of the steel tube, $\xi=A_{s} f_{y f} / A_{c} f_{c k}$, and $f_{\mathrm{ck}}$ refers to the standard value of $f_{\mathrm{ck}}$ of concrete calculated from the measured value.

skeleton curves of 22 STHCCs are shown in Figure 8. It is noteworthy that the skeleton curves can be roughly divide into three stages: elastic deformation stage, elastic-plastic stage, and load decline stage, which are similar to the loaddisplacement curves of the specimens obtained by axial compression tests. The skeleton curves of the specimens show a linear trend at the initial loading stage; at the same time, the specimens show elastic deformation. With the increase of horizontal load, the skeleton curves change into nonlinear gradually, and elastic-plastic deformation appears for the steel tubes. The plastic damage of concrete continues to accumulate until the load reaches the peak load. After the peak load, the skeleton curves begin to decline. It is demonstrated that the specimens show excellent bearing capacity.

With the increase of $\lambda_{s}$, the initial stiffness of the specimens and the bearing capacity gradually decrease; it can be found that the magnitude of the decline of skeleton curves slows down gradually, as shown in Figure 8(a). Figures 8(b) and $8(\mathrm{c})$ show that the influence of $n(n<0.4)$ and $f_{\mathrm{ck}}$ $\left(f_{\text {ck }}<60 \mathrm{MPa}\right)$ on the bearing capacity of the specimens is not obvious and that the slope of the curves is similar. Figures 8(d) and 8(e) show that with the increase of $\alpha$ and $f_{\mathrm{yfk}}$, the bearing capacity and deformation capacity increase obviously. Figures 8(f) and 8(g) show that with the increase of $D / B$, the slope of the descending stage of the skeleton curves decreases gradually.

\subsection{Establishment of Skeleton Curve Model and Restoring Force Model}

6.3.1. Simplified Skeleton Curve Model. In order to obtain the characteristics of STHCC skeleton curves, the skeleton curves should be normalized firstly [25], as shown in Figure 9. 


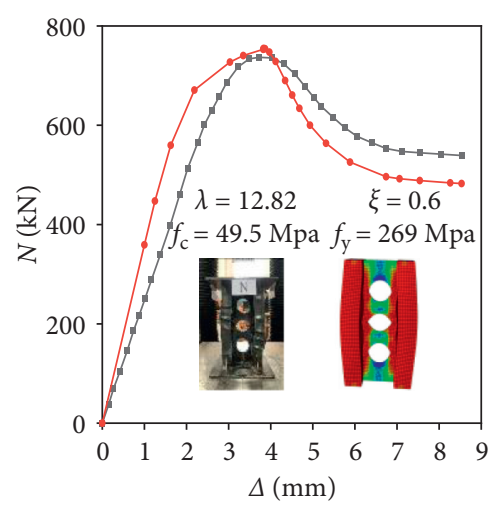

$\rightarrow$ Test curve (J. Ji [5])

$\rightarrow$ Simulation curve

(a)

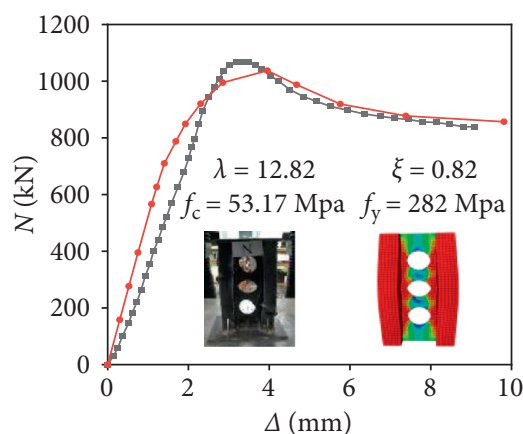

$\neg$ Test curve (J. Ji [5])

$\rightarrow$ Simulation curve

(d)

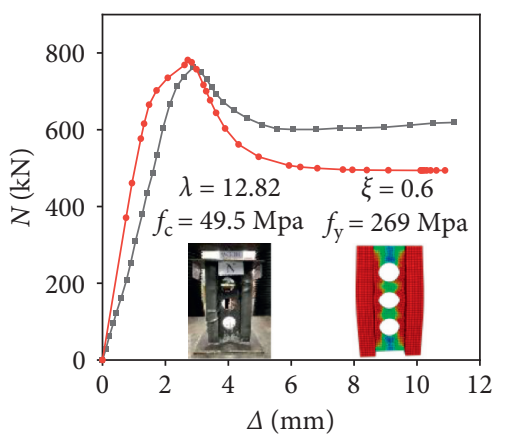

— Test curve (J. Ji [5])

$\rightarrow$ Simulation curve

(g)

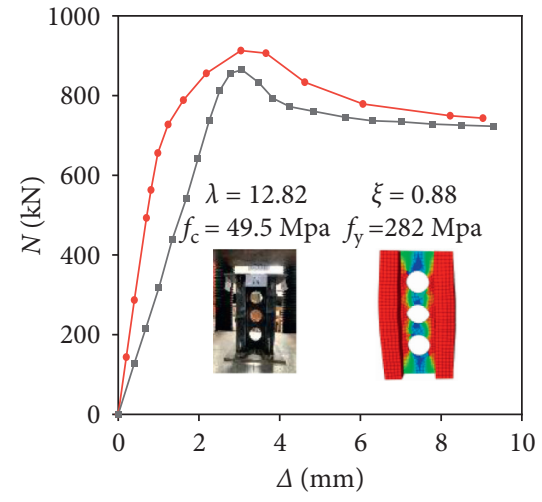

$\longrightarrow$ Test curve (J. Ji [5])

$\rightarrow$ Simulation curve

(b)

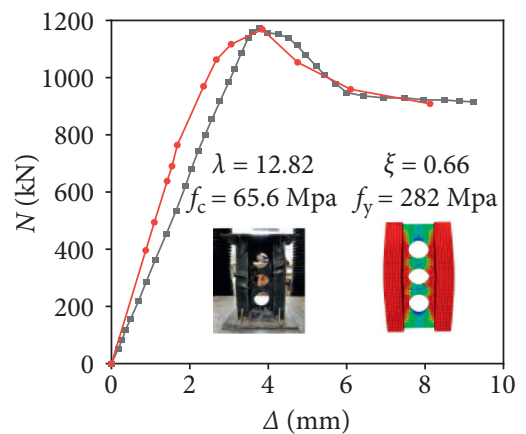

$\longrightarrow$ Test curve (J. Ji [5])

$\rightarrow$ Simulation curve

(e)

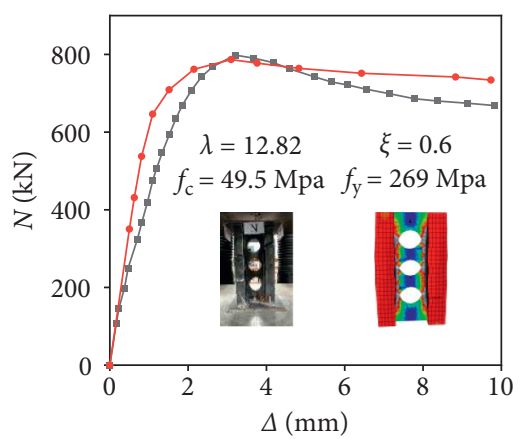

$\rightarrow$ Test curve (J. Ji [5])

(h)

Figure 4: Continued.

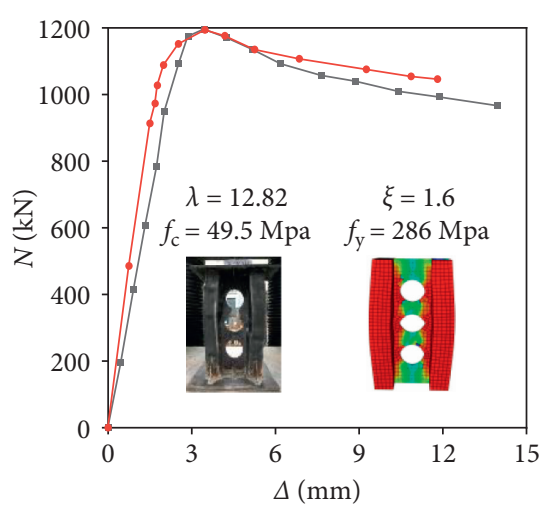

$\rightarrow$ Test curve (J. Ji [5])

$\rightarrow$ Simulation curve

(c)

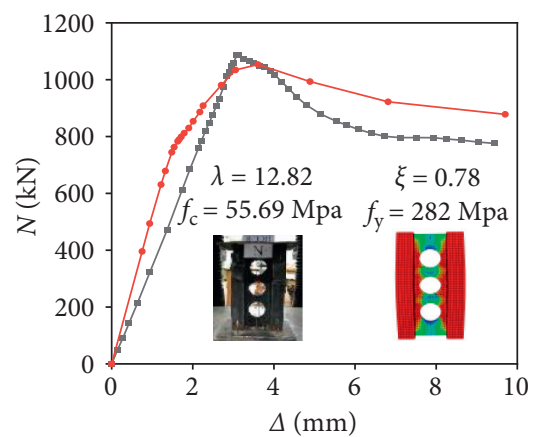

$\rightarrow$ Test curve (J. Ji [5])

$\rightarrow$ Simulation curve

(f)

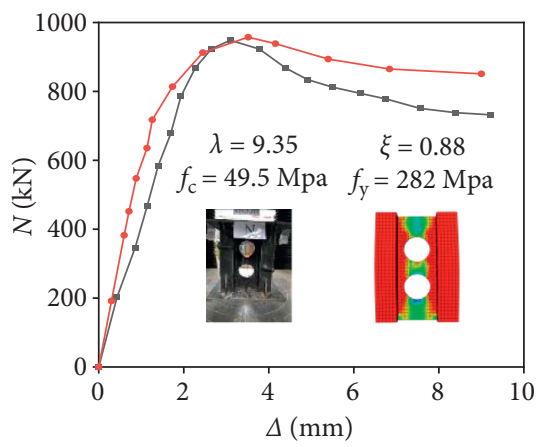

- Test curve (J. Ji [5])

- Simulation curve

(i) 


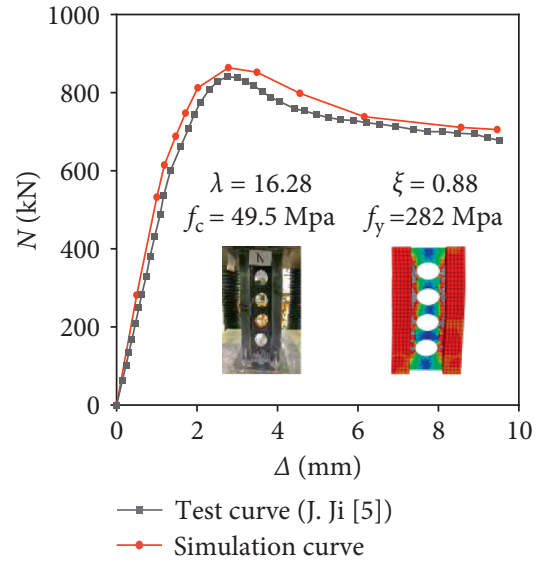

(j)

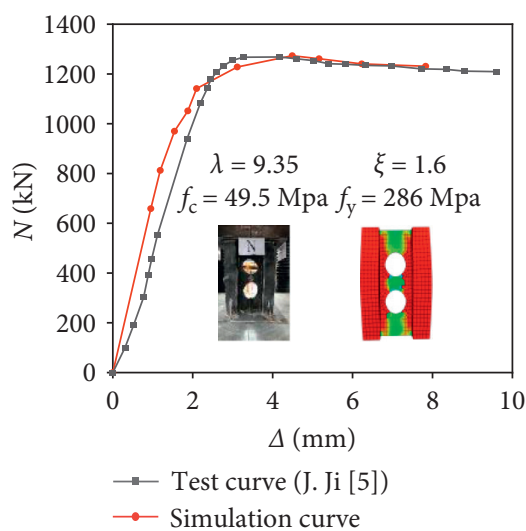

$(\mathrm{m})$

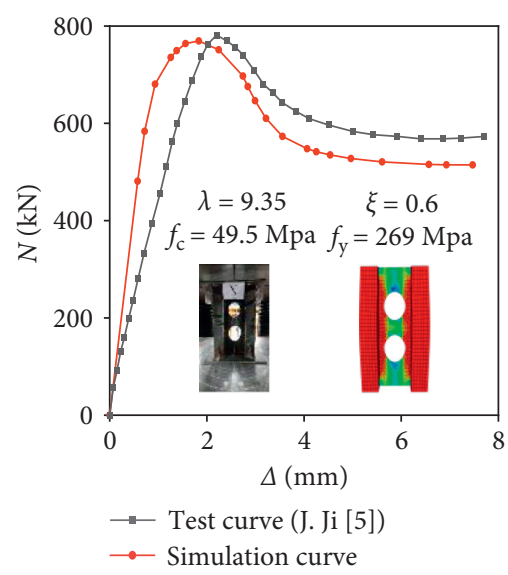

$(\mathrm{k})$

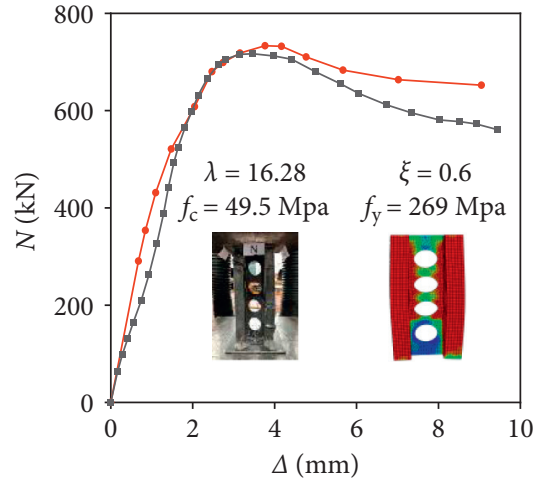

Test curve (J. Ji [5])

$\rightarrow$ Simulation curve

(1)

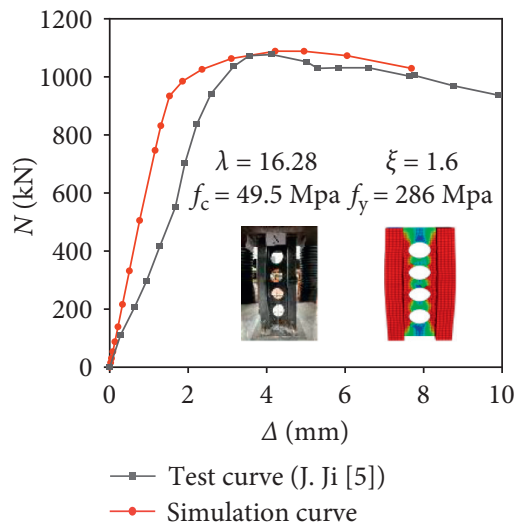

(n)

Figure 4: Comparisons of load-displacement curves between simulation and test results. (a) STHCC1. (b) STHCC2. (c) STHCC3. (d) STHCC4. (e) STHCC5. (f) STHCC6. (g) STHCC7. (h) STHCC8. (i) STHCC9. (j) STHCC10. (k) STHCC11. (l) STHCC12. (m) STHCC13. (n) STHCC14.

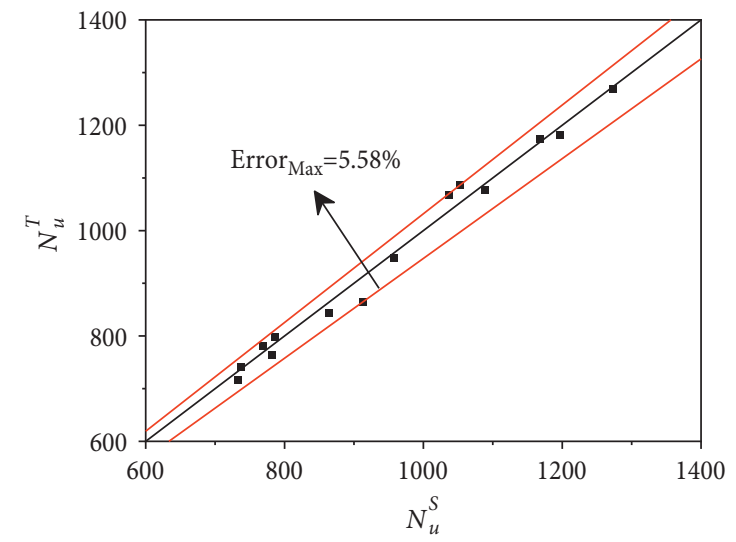

FIgURE 5: Comparison between $N_{u}^{T}$ and $N_{u}^{S}$ of 14 STHCCs.

It can be found from Figure 9 that the skeleton curves conform to the trilinear law $[26,27]$, which can be simplified as a calculation model, as shown in Figure 10, and the specific simplified rules are as follows:
(1) A trilinear model consists of three stages: elastic stage, elastic-plastic stage, and decline stage, where the yield point, peak point, and limit point are considered. 


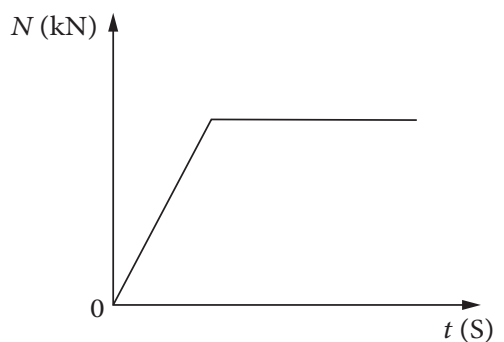

(a)
$P(\mathrm{kN})$

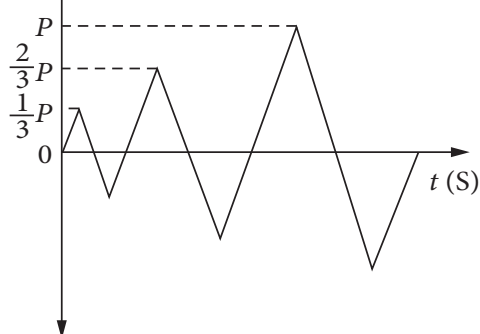

(b)

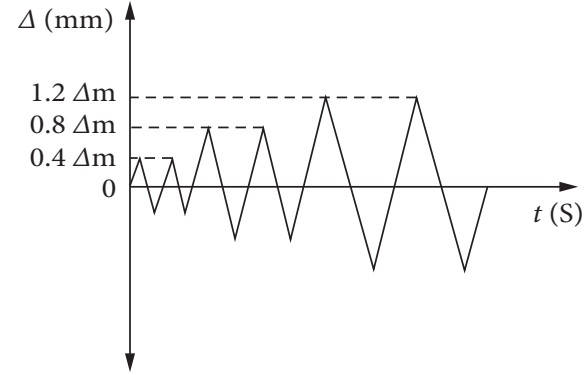

(c)

FIgURE 6: Loading procedure. (a) Axial force loading. (b) Single-cycle loading of lateral force. (c) Double-cycle loading of lateral displacement.

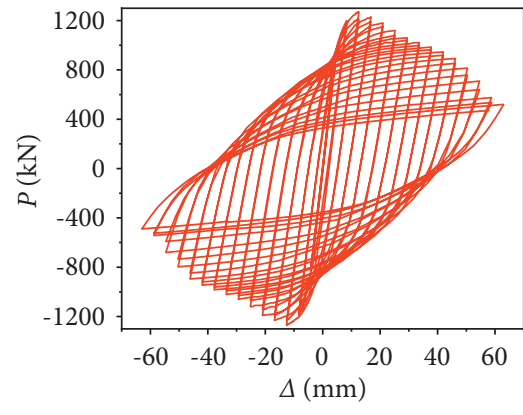

- STHCC-1

(a)

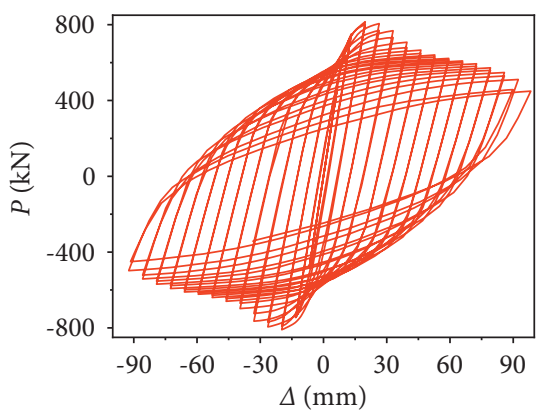

- STHCC-4

(d)

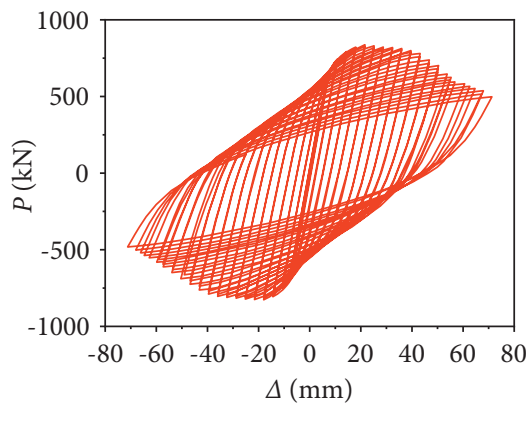

— STHCC-7

(g)

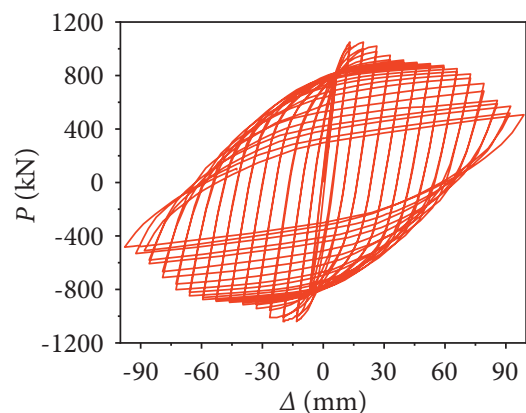

- STHCC-2

(b)

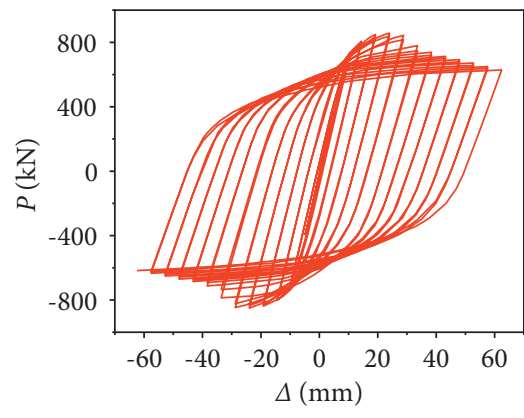

- STHCC-5

(e)

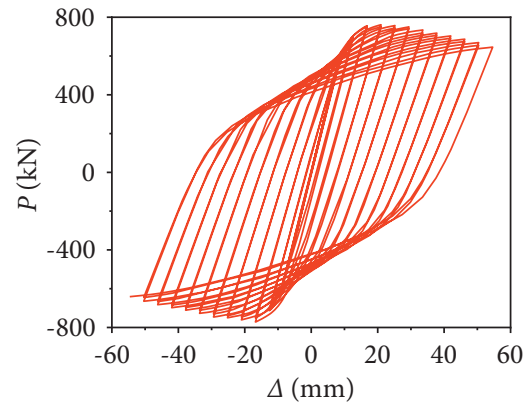

- STHCC-8

(h)

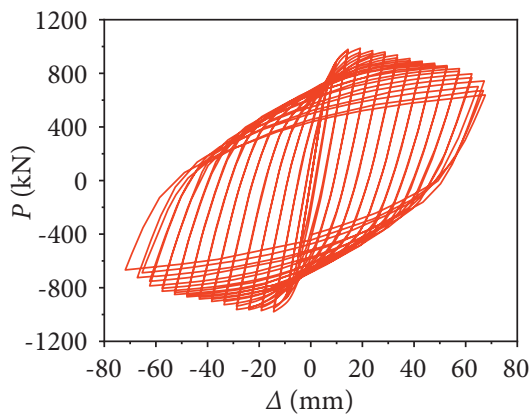

- STHCC-3

(c)

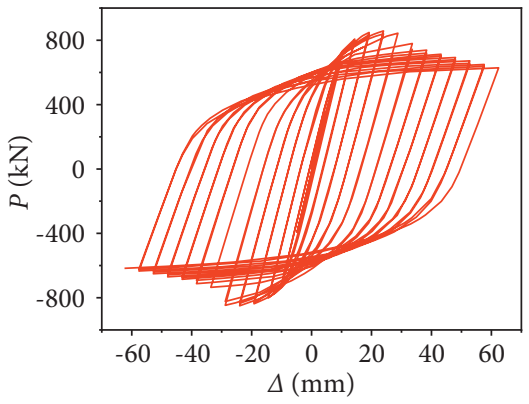

— STHCC-6

(f)

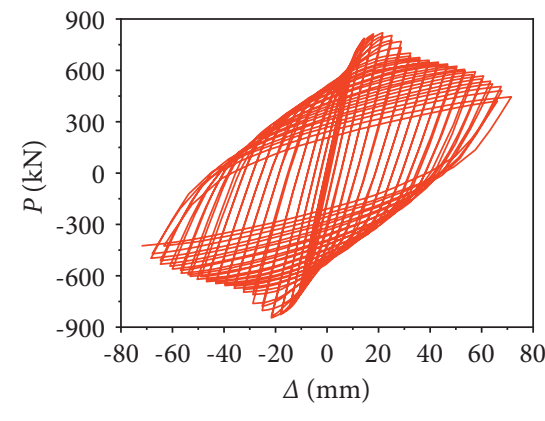

- STHCC-9

(i)

Figure 7: Continued. 


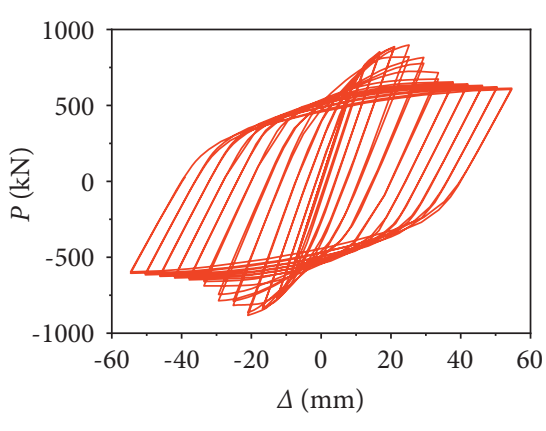

- STHCC-10

(j)

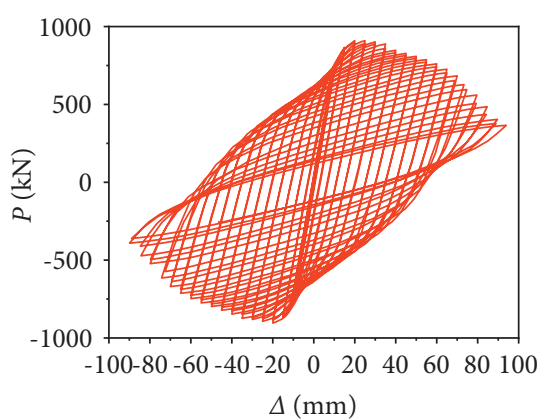

— STHCC-13

(m)

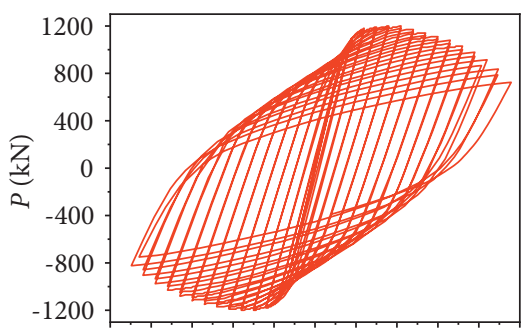

$-100-80-60-40-20 \quad 0 \quad 20 \quad 40 \quad 60 \quad 80100$ $\Delta(\mathrm{mm})$

— STHCC-16

(p)

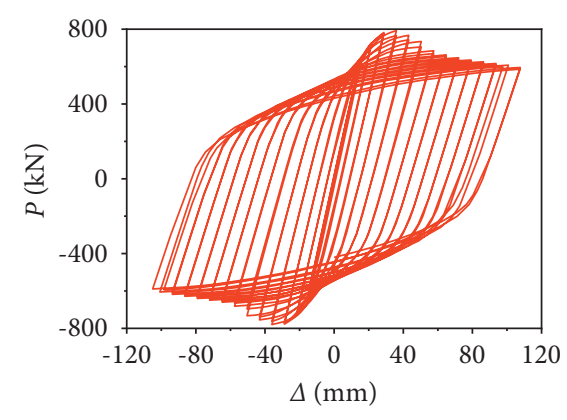

- STHCC-19

(s)

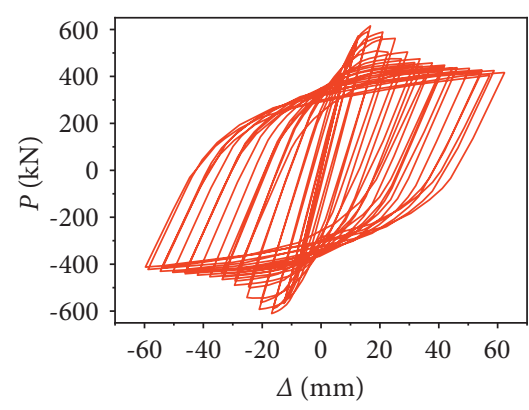

— STHCC-11

(k)

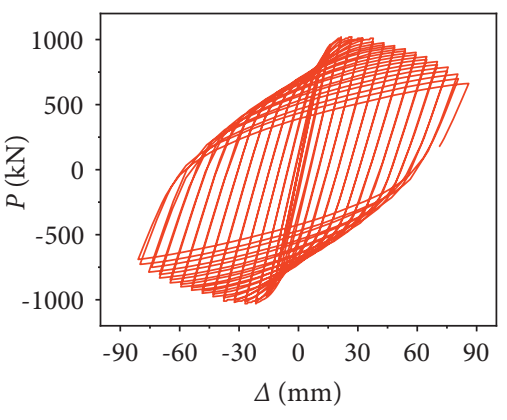

- STHCC-14

(n)

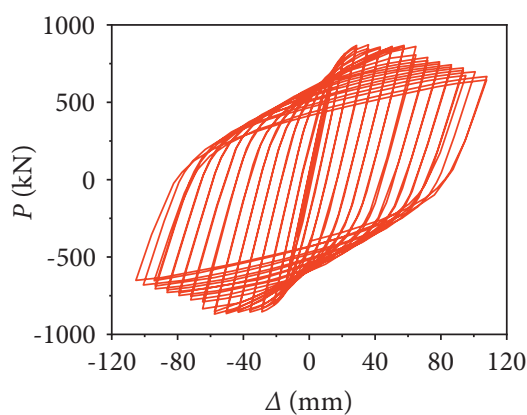

— STHCC-17

(q)

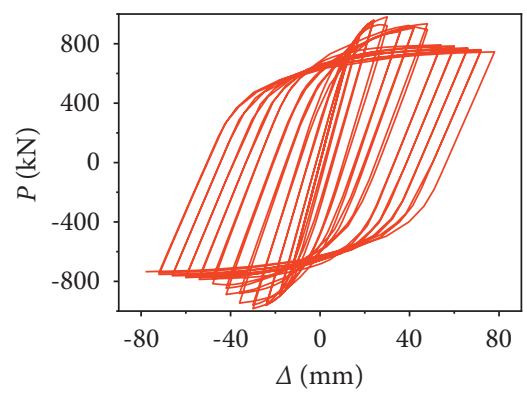

— STHCC-20

(t)

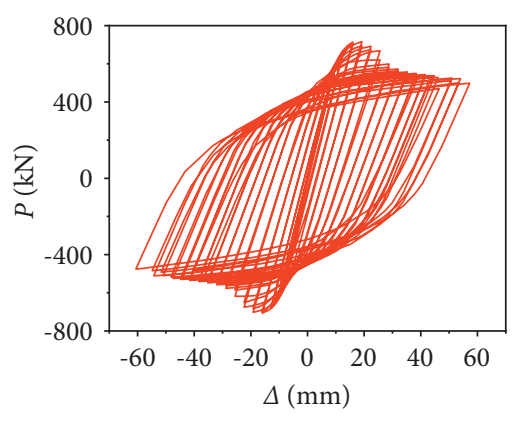

— STHCC-12

(1)

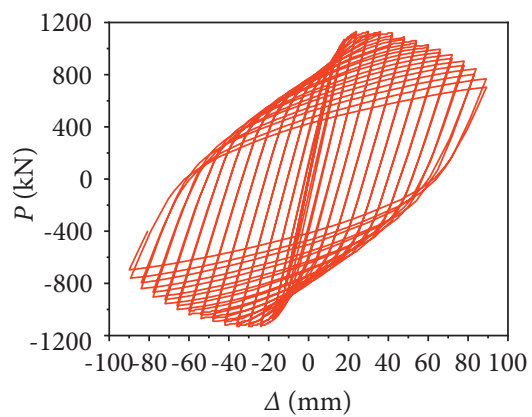

— STHCC-15

(o)

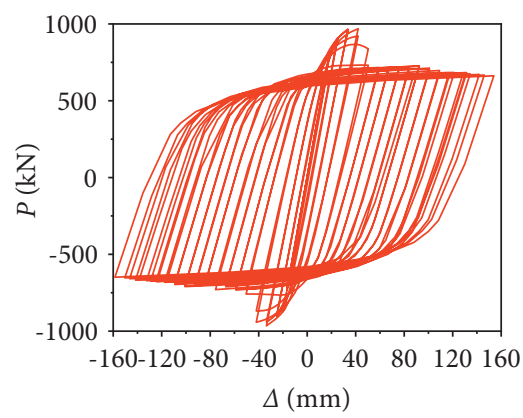

— STHCC-18

(r)

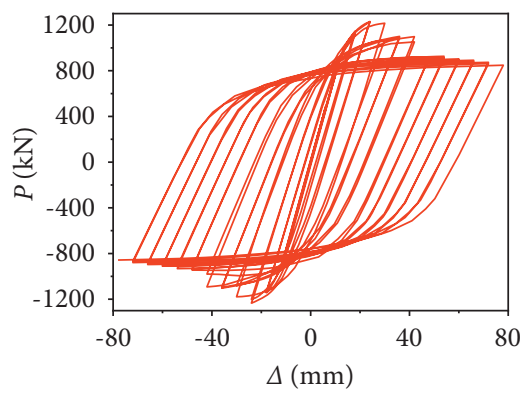

— STHCC-21

(u)

Figure 7: Continued. 


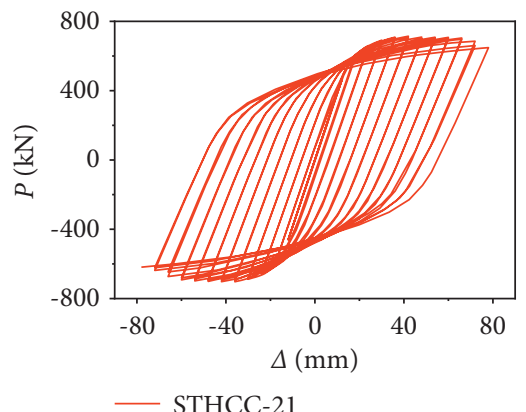

(v)

Figure 7: Hysteresis curves of 22 STHCCs. (a) STHCC1. (b) STHCC2. (c) STHCC3. (d) STHCC4. (e) STHCC5. (f) STHCC6. (g) STHCC7. (h) STHCC8. (i) STHCC9. (j) STHCC10. (k) STHCC11. (l) STHCC12. (m) STHCC13. (n) STHCC14. (o) STHCC15. (p) STHCC16. (q) STHCC17. (r) STHCC18. (s) STHCC19. (t) STHCC20. (u) STHCC21. (v) STHCC22.

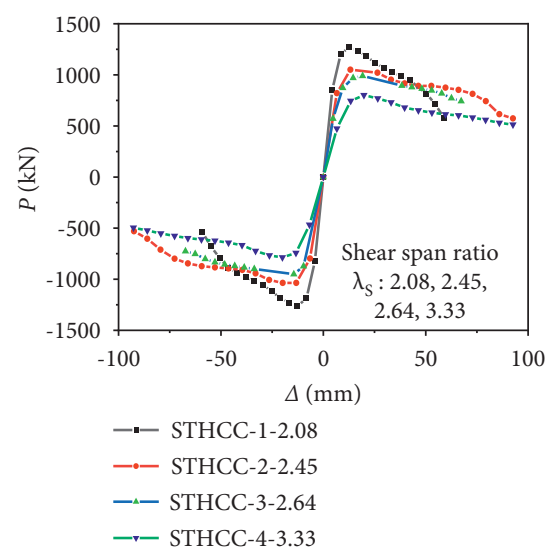

(a)

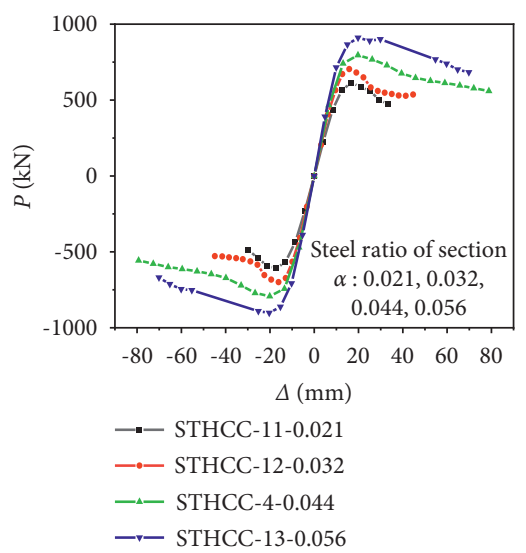

(d)

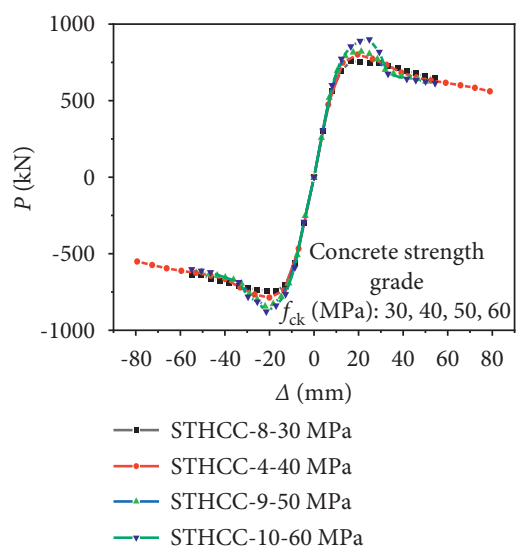

(b)

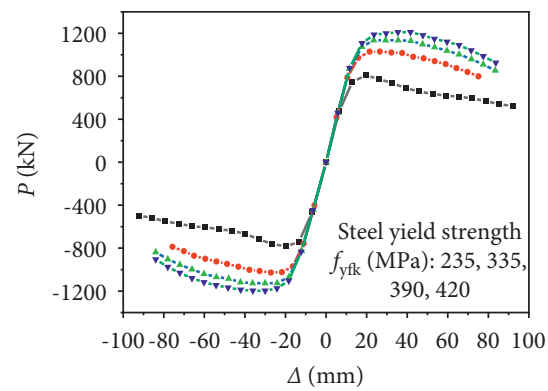

$\rightarrow-$ STHCC-4-235 MPa

-־ STHCC-14-335 MPa

- - STHCC-15-390 MPa

$\rightarrow$ - STHCC-16-42 0MPa

(e)

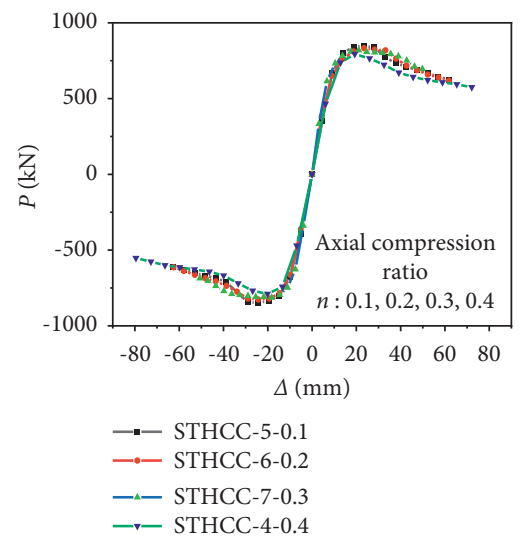

(c)

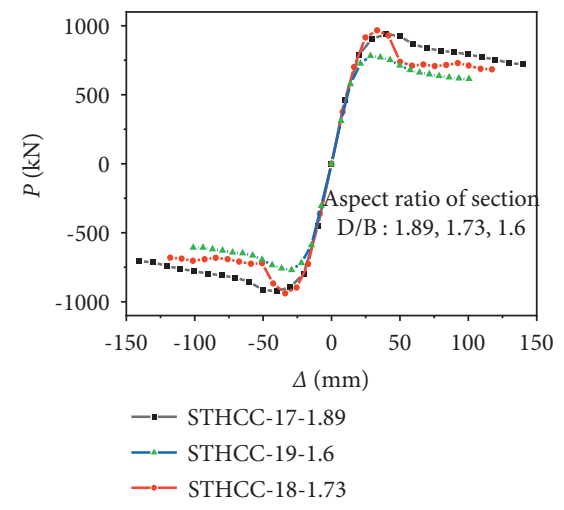

(f)

Figure 8: Continued. 


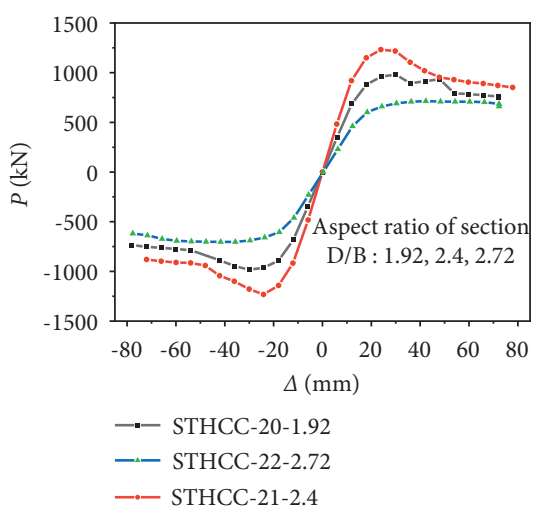

(g)

FIGURE 8: Skeleton curves of STHCCs with different parameters. (a) $\lambda_{s}: 2.08,2.45,2.64,3.33$. (b) $f_{\text {ck }}: 30 \mathrm{MPa}, 40 \mathrm{MPa}, 50 \mathrm{MPa}, 60 \mathrm{MPa}$. (c) $n$ : $0.1,0.2,0.3,0.4$. (d) $\alpha: 0.021,0.032,0.044,0.056$. (e) $f_{\text {yfk }}: 235 \mathrm{MPa}, 335 \mathrm{MPa}, 390 \mathrm{MPa}, 420 \mathrm{MPa}$. (f) $D / B: 1.89,1.73,1.6$. (g) $D / B: 1.92,2.4,2.72$.

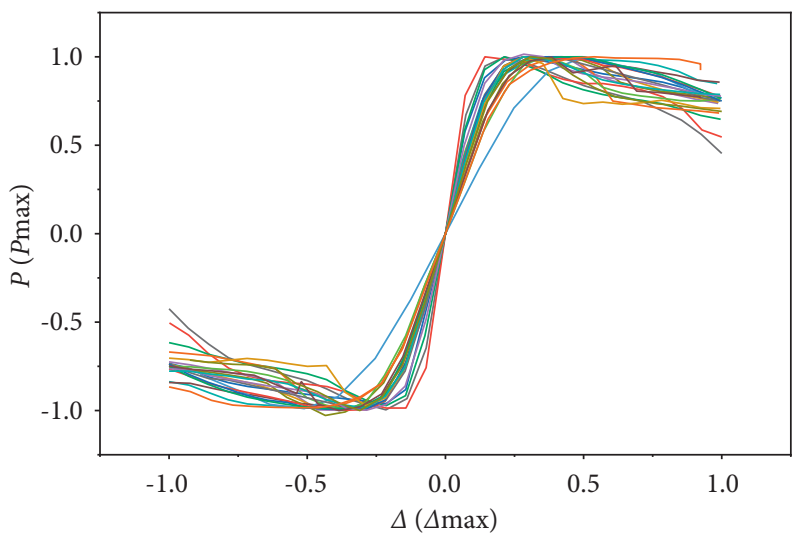

Figure 9: Skeleton curves of 22 STHCC specimens.

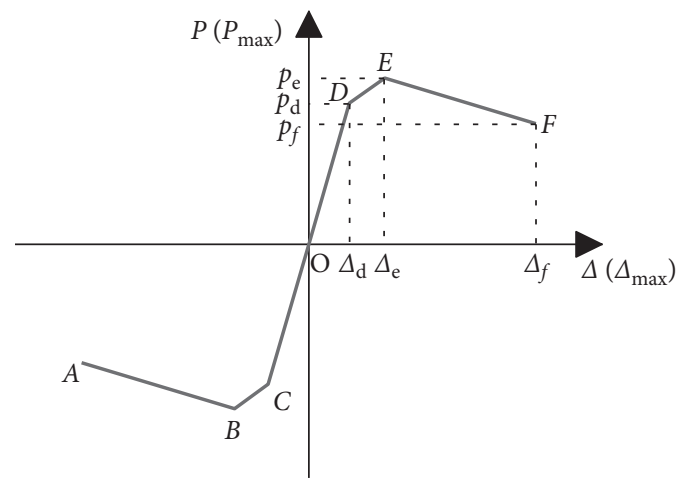

FIgURE 10: Trilinear skeleton curve model for 22 STHCC specimens.

(2) The values of characteristic points for skeleton curve model are the average positive direction and negative direction values of characteristic points for each specimen.

(3) It is considered that the specimens are at the elastic stage before yield point; hence, the elastic stiffness is selected as the stiffness. When the load value raises between the yield point and the peak point, the specimen is considered to be at the elastic-plastic stage. After the peak point, there comes a declining stage, in which the stiffness of the specimens remains at the same value, and the equation of the skeleton curve is shown in Table 3.

6.3.2. Comparisons of Regression Values and Simulation Values of the Skeleton Curves. The comparisons of calculation results and simulation results of the skeleton curves for 22 specimens are illustrated in Figure 11. It can be found 
TABLE 3: The equation of the skeleton curve.

\begin{tabular}{|c|c|c|}
\hline Section & Regression equation & Slope \\
\hline OD & $P / P_{\max }^{+}=4.81\left(\Delta / \Delta_{\max }^{+}\right)$ & 4.81 \\
\hline $\mathrm{DE}$ & $P / P_{\max }^{+}=0.98\left(\Delta / \Delta_{\max }^{+}\right)+0.68$ & 0.98 \\
\hline $\mathrm{EF}$ & $P / P_{\max }^{+}=-0.42\left(\Delta / \Delta^{+}{ }_{\max }\right)+1.14$ & -0.42 \\
\hline $\mathrm{OC}$ & $P / P_{\max }^{-}=4.73\left(\Delta / \Delta^{-} \max \right)$ & 4.73 \\
\hline $\mathrm{CB}$ & $P / P_{\max }^{-}=1.00\left(\Delta / \Delta_{\max }^{-}\right)-0.66$ & 1.00 \\
\hline $\mathrm{BA}$ & $P / P_{\max }^{-}=-0.41\left(\Delta / \Delta_{\text {max }}^{-}\right)-1.12$ & -0.41 \\
\hline
\end{tabular}

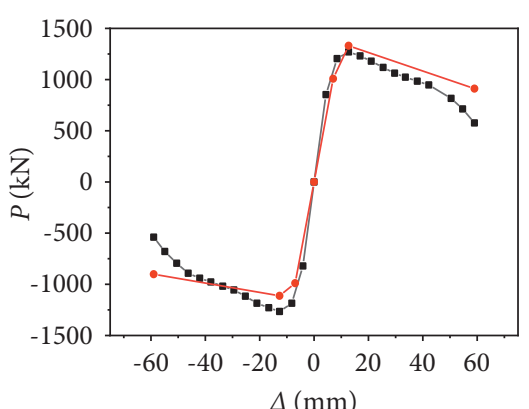

-. Simulation curve

$\rightarrow-$ Fitting curve

(a)

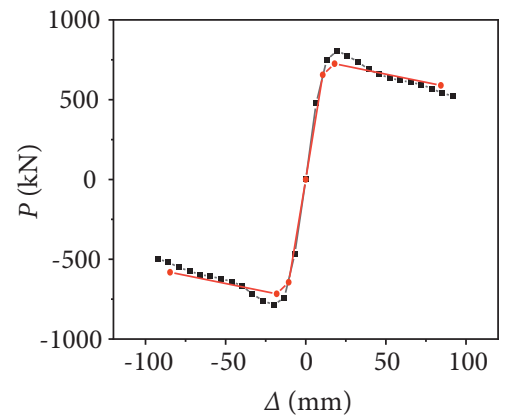

-- Simulation curve

-. Fitting curve

(d)

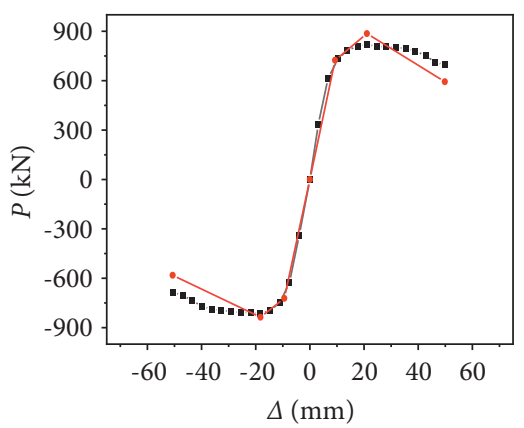

- Simulation curve

-- Fitting curve

(g)

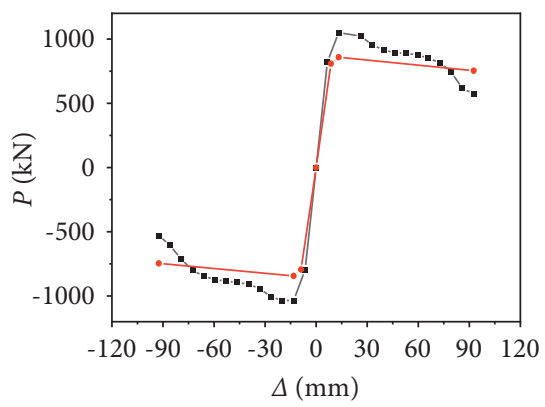

$\rightarrow$ Simulation curve

-- Fitting curve

(b)

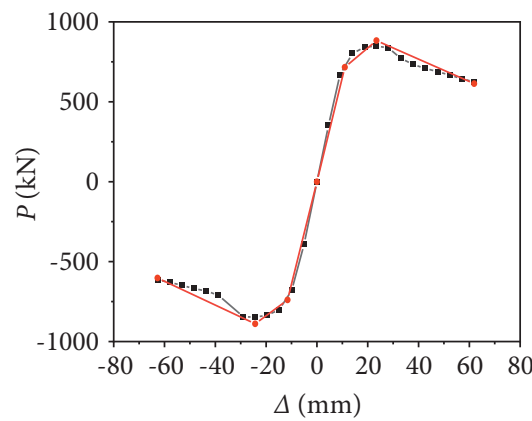

-.- Simulation curve

-- Fitting curve

(e)

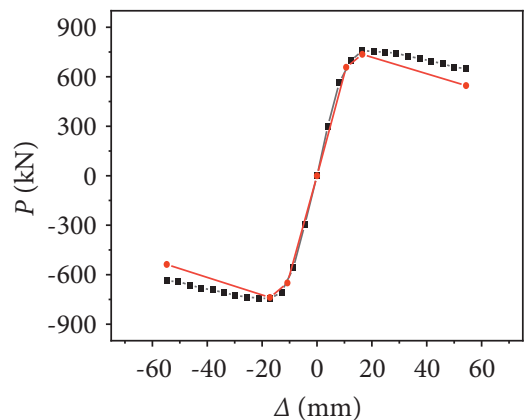

-- Simulation curve

- Fitting curve

(h)

Figure 11: Continued.

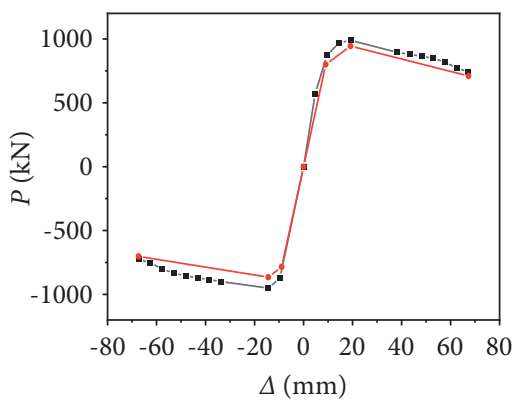

$\rightarrow-$ Simulation curve

-- - Fitting curve

(c)

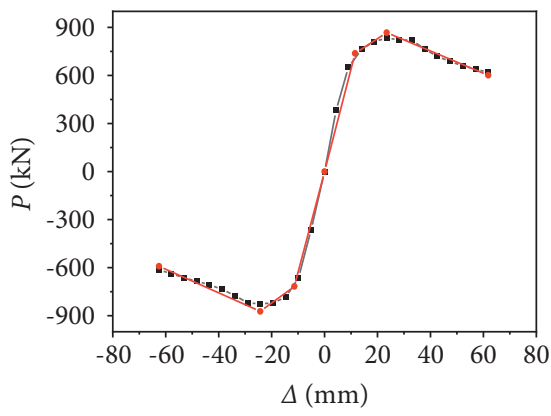

-.- Simulation curve

-. Fitting curve

(f)

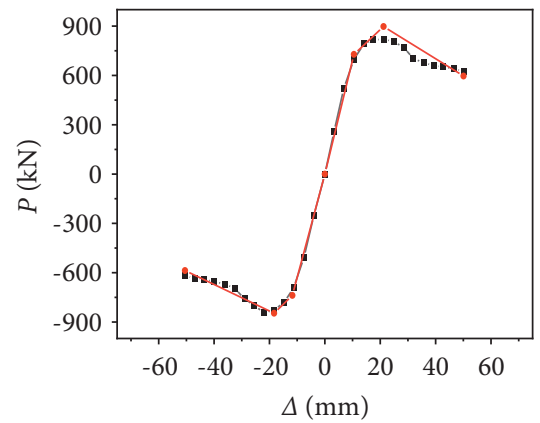

- - Simulation curve

-- Fitting curve

(i) 


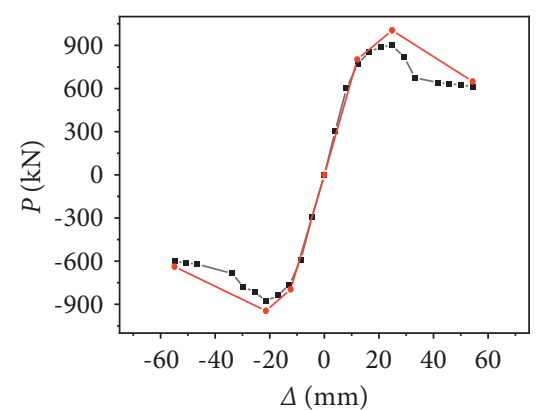

$\rightarrow-$ Simulation curve

-.- Fitting curve

(j)

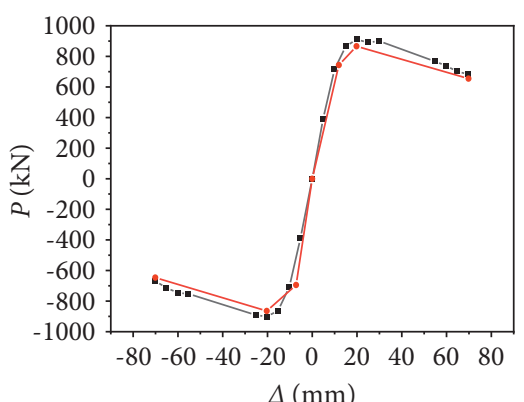

-.- Simulation curve

-- Fitting curve

(m)

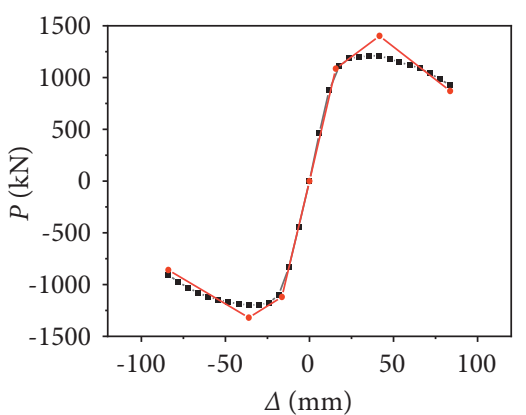

-. Simulation curve

-- Fitting curve

(p)

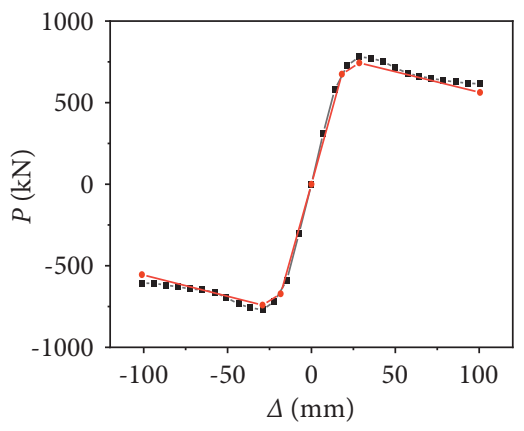

-.- Simulation curve

- - Fitting curve

(s)

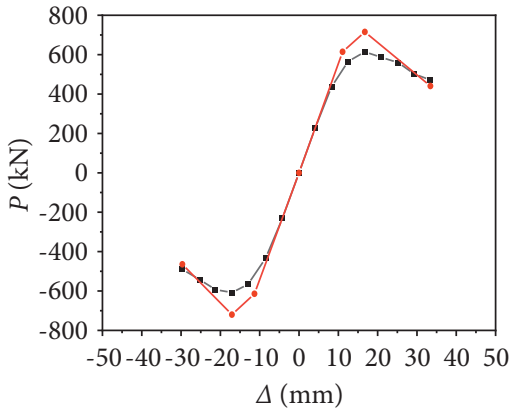

- Simulation curve

-- Fitting curve

(k)

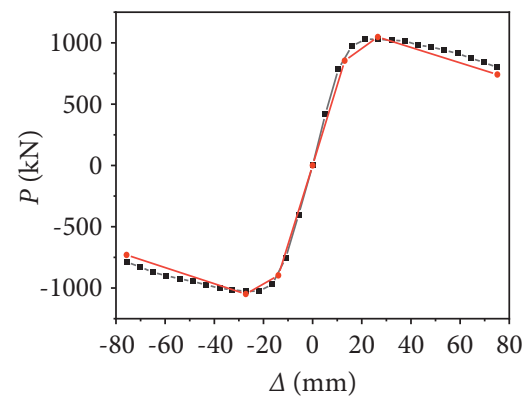

--- Simulation curve

-- - Fitting curve

(n)

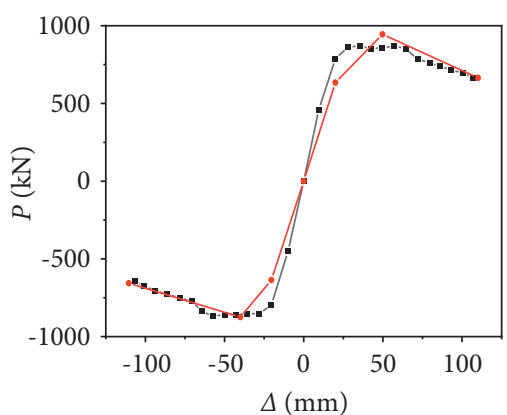

- - Simulation curve

-. Fitting curve

(q)

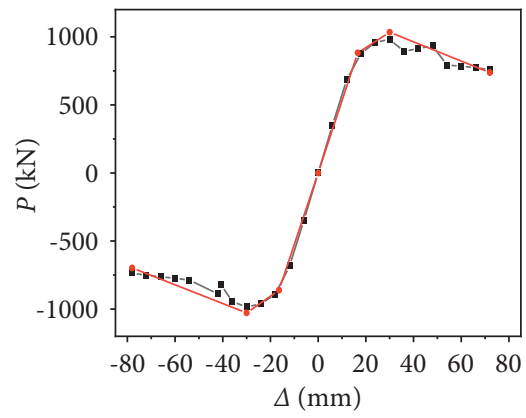

-- Simulation curve

-- Fitting curve

(t)

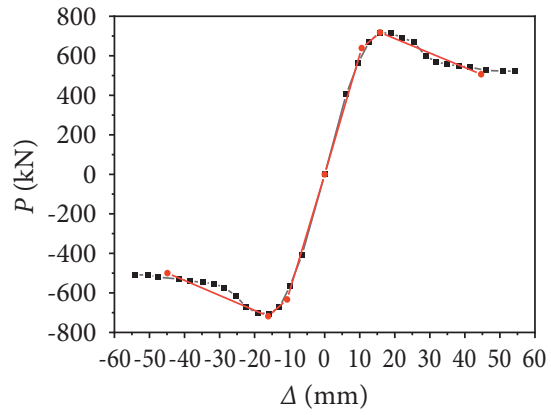

-. Simulation curve

-- Fitting curve

(l)

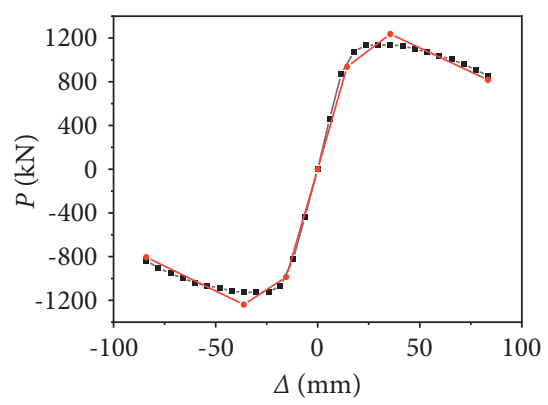

-- Simulation curve

--- Fitting curve

(o)

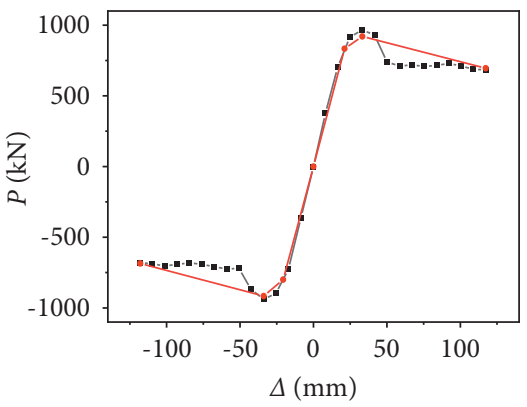

-- Simulation curve

-.- Fitting curve

(r)

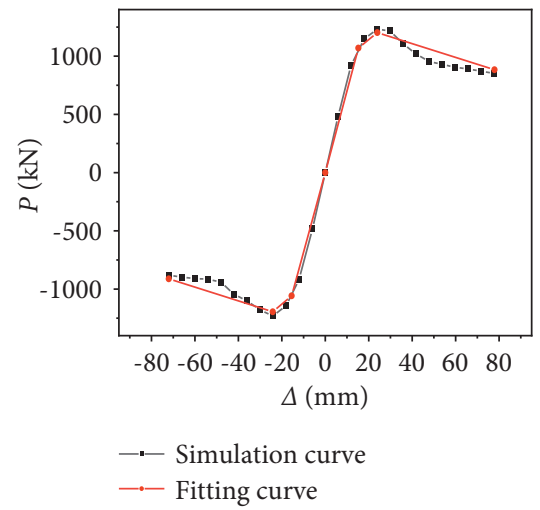

(u)

Figure 11: Continued. 


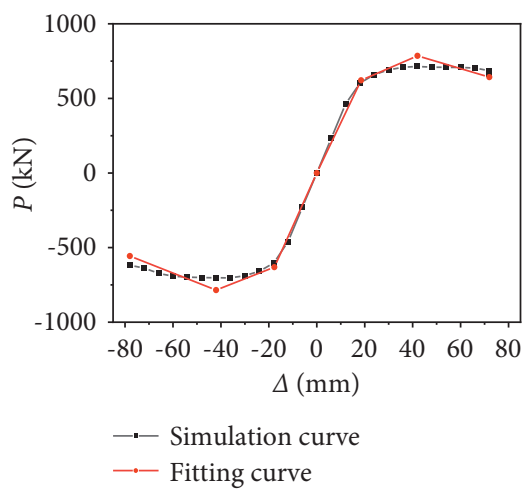

(v)

FIGURE 11: Comparisons of skeleton curve model between calculation and simulation. (a) STHCC1. (b) STHCC2. (c) STHCC3. (d) STHCC4. (e) STHCC5. (f) STHCC6. (g) STHCC7. (h) STHCC8. (i) STHCC9. (j) STHCC10. (k) STHCC11. (l) STHCC12. (m) STHCC13. (n) STHCC14. (o) STHCC15. (p) STHCC16. (q) STHCC17. (r) STHCC18. (s) STHCC19. (t) STHCC20. (u) STHCC21. (v) STHCC22.

that the calculation results are in good agreement with the simulation results, which indicates that the skeleton curve model obtained by statistical regression can reflect the loaddisplacement relationships accurately.

6.4. Stiffness Degradation. The stiffness of the specimens is reflected by the secant stiffness $\left(K_{i}\right)[10,28]$, which could be expressed by

$$
K_{i}=\frac{\left|+P_{i}\right|+\left|-P_{i}\right|}{\left|+\Delta_{i}\right|+\left|-\Delta_{i}\right|},
$$

where $P_{i}$ denotes peak horizontal load of the first cycle under the $i$-th control displacement and $\Delta_{i}$ refers to the corresponding displacement.

The secant stiffness $\left(K_{i}\right)$ versus the horizontal displacement $(\Delta)$ relationships of 22 STHCCs are shown in Figure 12. It can be seen from Figure 12 that the stiffness degradation trends of STHCCs are similar. $K_{i}$ shows a decreasing trend with the increase of $\Delta$, and the curves gradually slow down with the increase of $\Delta . \lambda_{s}, \alpha, D / B$, and $f_{\mathrm{yfk}}$ have a significant impact on the secant stiffness, and with the increase of $\lambda_{s}, \alpha$, and $f_{\mathrm{yfk}}$, the stiffness degradation rate of the specimen gradually slows down. With the increase of $D / B$, the stiffness degradation rate of the specimen improves, and the stiffness degradation phenomenon becomes more significant.

6.4.1. Degradation Law of Stiffness. It is found that the secant stiffness of the specimens decreases constantly during the whole loading and unloading process. In Figure 13, point 1 represents the $i$-th horizontal load peak point under forward loading, and point 2 represents the $i$-th horizontal load peak point under reverse loading. The slope of the line from point 1 to point 2 expresses secant stiffness. The relationships between $K_{i} / K_{0}$ and $\Delta_{i} / \Delta_{\max }$ can be obtained by statistical regression based on the test results, as shown in Figure 14. The regression formula is expressed as follows:

$$
K_{i} / K_{0}=1.221 e^{-3.023 \Delta_{i} / \Delta_{\max }}+0.045,
$$

where $K_{i}$ denotes the secant stiffness of the first stage horizontal load peak under the $i$-th control displacement and $\Delta_{i}$ refers to the $i$-th control displacement.

6.5. Ductility. Ductility is regarded as a main parameter to measure the deformation performance of the specimens [29], and it can be explained by the ductility coefficient $(\mu)$, which can be calculated by the following equation:

$$
\mu=\frac{\left(\left|\Delta_{u}^{+}\right|+\left|\Delta_{u}^{-}\right|\right)}{\left(\left|\Delta_{y}^{+}\right|+\left|\Delta_{y}^{-}\right|\right)},
$$

where $\Delta_{u}^{+}, \Delta_{y}^{+}$refer to positive limit displacement and yield displacement, respectively, and $\Delta_{u}^{-}, \Delta_{y}^{-}$denote negative limit displacement and yield displacement, respectively.

6.5.1. Simulation Results. The ductility coefficients of 22 specimens determined by the above-mentioned calculation method are shown in Table 4. The existing research $[25,30,31]$ shows that $\mu$ of steel reinforced concrete (SRC) columns ranges from 3.50 to 6.00 when $\lambda_{s}$ value is greater than 2. Table 4 shows that the ductility of STHCCs is similar to that of SRC columns, which indicates that the specimens have good deformation behavior.

6.5.2. Shear Span Ratio. The relationships between $P_{u}, \mu$, and $\lambda_{s}$ of the STHCCs are shown in Figure 15. With the increase of $\lambda_{s}, P_{u}$ and $\mu$ of the STHCCs decrease gradually. When $\lambda_{s}$ changes from 2.08 to $2.45,2.64,3.33$ in turn, $P_{u}$ of STHCCs decreases by $17.32 \%, 5.97 \%$, and $18.92 \%$, respectively, and $\mu$ decreases by $9.21 \%, 1.01 \%$, and $45.83 \%$, respectively.

6.5.3. Axial Compression Ratio. The relationships between $P_{u}, \mu$, and $n$ of the STHCCs are shown in Figure 16. It can be seen from Figure 16 that when $n$ changes from 0.1 to $0.3, P_{u}$ of the STHCCs decreases by $1.92 \%$ and $1.81 \%$, respectively, and $\mu$ increases by $8.93 \%$ and $85.76 \%$, respectively, in which $n$ has a significant effect on the ductility of the STHCCs. 


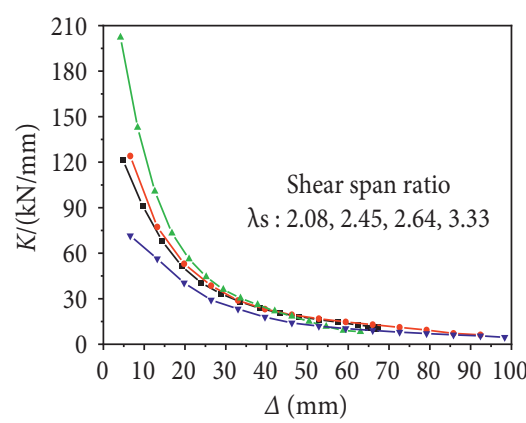

$-{ }_{-1}-$ STHCC-1-2.08 - - STHCC-3-2.64 -•- STHCC-2-2.45 - - STHCC-4-3.33

(a)

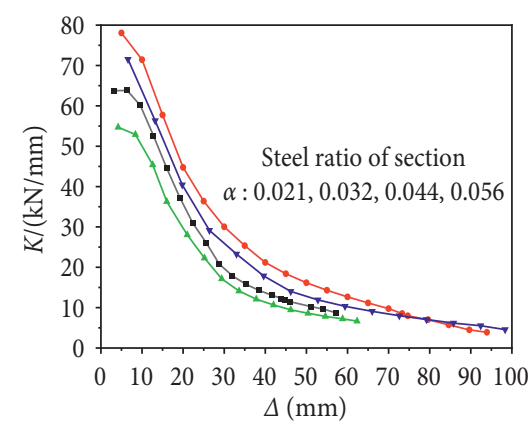

$\longrightarrow$ STHCC-11-0.021 $\longrightarrow$ STHCC-4-0.044

$\longrightarrow$ STHCC-12-0.032 $\longrightarrow$ STHCC-13-0.056

(d)

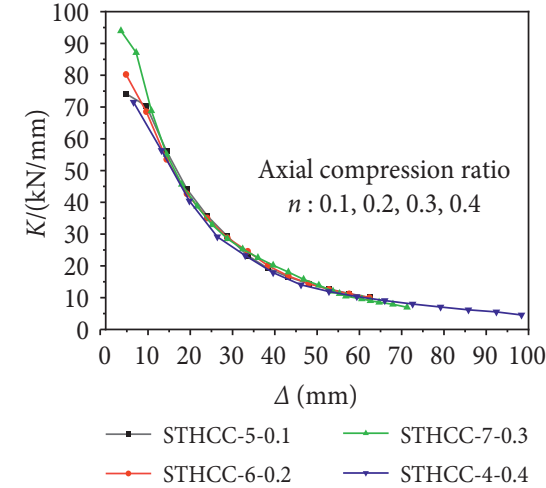

(b)

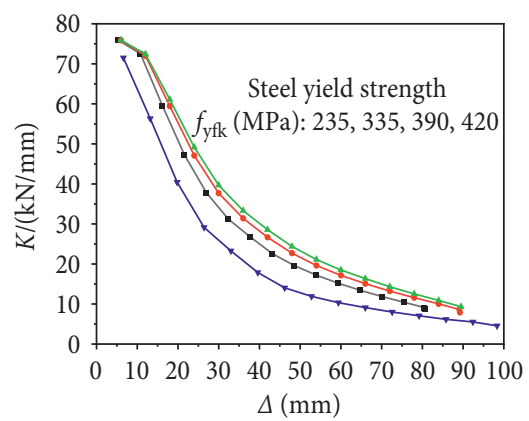

$\longrightarrow$ STHCC-14-345 MPa $\longrightarrow$ STHCC-16-420 MPa $\longrightarrow$ STHCC-15-390 MPa $\longrightarrow$ STHCC-4-235 MPa

(e)

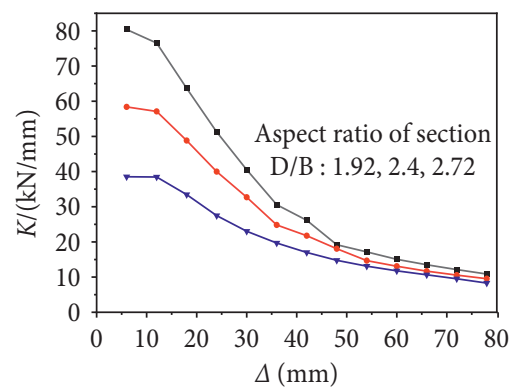

$\because$ STHCC-22-2.72 $\rightarrow$ STHCC-21-2.4

$\longrightarrow$ STHCC-20-1.92

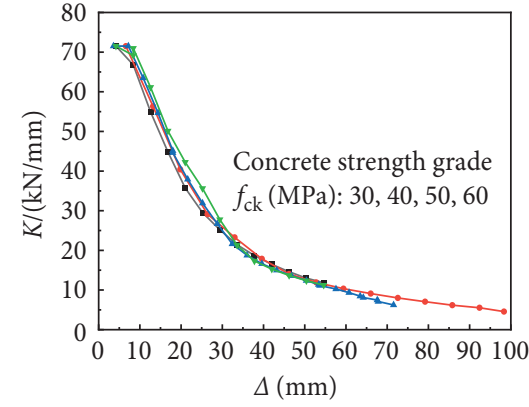

- STHCC-8-30 MPa $\longrightarrow$ STHCC-9-50 MPa

$\rightarrow$ STHCC-4-40 MPa $\longrightarrow$ STHCC-10-60 MPa

(c)

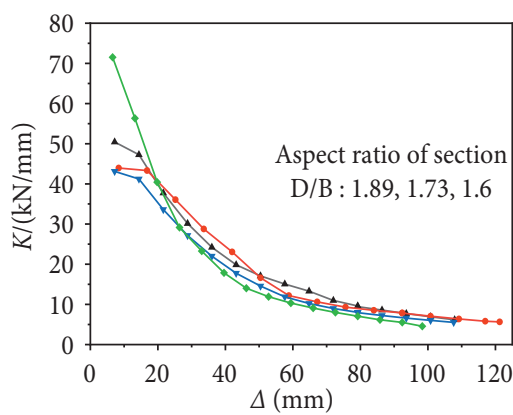

$\rightarrow$ STHCC-17-1.89 $\rightarrow$ STHCC-19-1.6 $\rightarrow$ STHCC-18-1.73 $\longrightarrow$ STHCC-4-2.08

(f)

(g)

FigURE 12: The relationships between $K_{i}$ and $\Delta$ for STHCCs with different parameters. (a) $\lambda_{s}: 2.08,2.45,2.64,3.33$. (b) $f_{\mathrm{ck}}: 30 \mathrm{MPa}, 40 \mathrm{MPa}$, $50 \mathrm{MPa}, 60 \mathrm{MPa}$. (c) $n: 0.1,0.2,0.3,0.4$. (d) $\alpha: 0.021,0.032,0.044,0.056$. (e) $f_{\mathrm{yfk}}: 235 \mathrm{MPa}, 335 \mathrm{MPa}, 390 \mathrm{MPa}, 420 \mathrm{MPa}$. (f) $D / B: 1.89,1.73,1.6$. (g) $D / B: 1.92,2.4,2.72$.

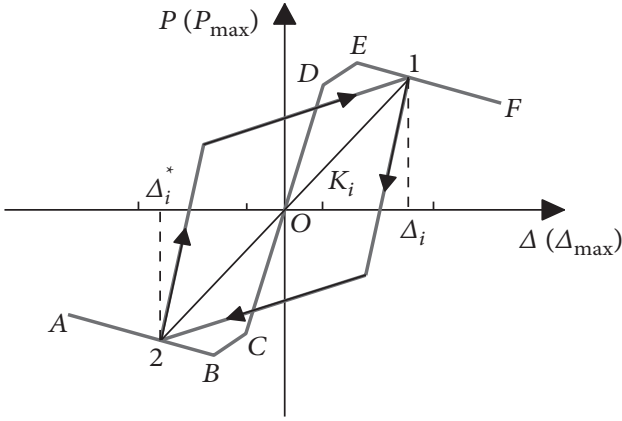

FIgURE 13: Stiffness degradation curve. 


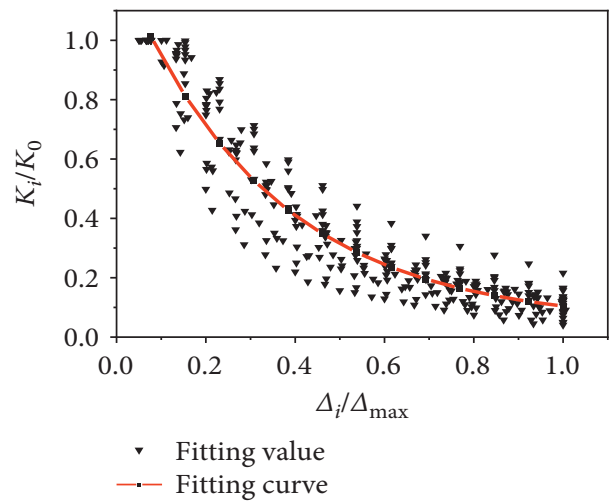

Figure 14: Relationships between $K_{i} / K_{0}$ and $\Delta_{i} / \Delta_{\max }$.

TABLE 4: Ductility coefficients of STHCC specimens.

\begin{tabular}{lcccccccccccc}
\hline Specimens & $\lambda_{s}$ & $n$ & $\alpha$ & $f_{\text {ck }}(\mathrm{MPa})$ & $f_{\mathrm{yfk}}(\mathrm{MPa})$ & $D / B$ & $P_{y}(\mathrm{kN})$ & $P_{u}(\mathrm{kN})$ & $\Delta_{\mathrm{y}}(\mathrm{mm})$ & $\Delta_{m}(\mathrm{~mm})$ & $\Delta_{u}(\mathrm{~mm})$ & $\mu$ \\
\hline STHCC1 & 2.08 & 0.4 & 0.044 & 40 & 235 & 2.08 & 1270.00 & 1079.50 & 4.33 & 12.60 & 29.40 & 6.78 \\
STHCC2 & 2.45 & 0.4 & 0.044 & 40 & 235 & 2.08 & 1050.00 & 892.50 & 7.50 & 19.80 & 46.20 & 6.16 \\
STHCC3 & 2.64 & 0.4 & 0.044 & 40 & 235 & 2.08 & 987.33 & 839.23 & 8.67 & 19.20 & 52.80 & 6.09 \\
STHCC4 & 3.33 & 0.4 & 0.044 & 40 & 235 & 2.08 & 800.51 & 680.43 & 12.00 & 19.80 & 39.60 & 3.30 \\
STHCC5 & 3.33 & 0.1 & 0.044 & 40 & 235 & 2.08 & 857.98 & 729.29 & 12.17 & 24.00 & 40.30 & 3.31 \\
STHCC6 & 3.33 & 0.2 & 0.044 & 40 & 235 & 2.08 & 841.51 & 715.28 & 12.33 & 24.00 & 44.50 & 3.61 \\
STHCC7 & 3.33 & 0.3 & 0.044 & 40 & 235 & 2.08 & 826.24 & 702.30 & 7.83 & 21.60 & 52.50 & 6.70 \\
STHCC8 & 3.33 & 0.4 & 0.044 & 30 & 235 & 2.08 & 753.01 & 640.06 & 10.50 & 16.80 & 54.60 & 5.20 \\
STHCC9 & 3.33 & 0.4 & 0.044 & 50 & 235 & 2.08 & 819.27 & 696.38 & 10.67 & 21.60 & 34.50 & 3.23 \\
STHCC10 & 3.33 & 0.4 & 0.044 & 60 & 235 & 2.08 & 897.57 & 762.93 & 13.00 & 25.20 & 33.60 & 2.58 \\
STHCC11 & 3.33 & 0.4 & 0.021 & 40 & 235 & 2.08 & 615.00 & 522.75 & 12.50 & 16.80 & 29.40 & 2.35 \\
STHCC12 & 3.33 & 0.4 & 0.032 & 40 & 235 & 2.08 & 706.41 & 600.45 & 10.67 & 16.00 & 25.60 & 2.40 \\
STHCC13 & 3.33 & 0.4 & 0.056 & 40 & 235 & 2.08 & 908.70 & 772.40 & 10.50 & 20.00 & 55.00 & 5.24 \\
STHCC14 & 3.33 & 0.4 & 0.044 & 40 & 345 & 2.08 & 1022.73 & 869.32 & 15.17 & 27.00 & 64.80 & 4.27 \\
STHCC15 & 3.33 & 0.4 & 0.044 & 40 & 390 & 2.08 & 1130.00 & 960.50 & 13.33 & 24.00 & 70.00 & 5.25 \\
STHCC16 & 3.33 & 0.4 & 0.044 & 40 & 420 & 2.08 & 1200.00 & 1020.00 & 13.33 & 36.00 & 72.00 & 5.40 \\
STHCC17 & 3.33 & 0.4 & 0.042 & 40 & 235 & 1.89 & 900.13 & 765.11 & 20.00 & 40.00 & 110.00 & 5.50 \\
STHCC18 & 3.33 & 0.4 & 0.041 & 40 & 235 & 1.73 & 961.00 & 816.85 & 17.67 & 33.60 & 57.20 & 3.24 \\
STHCC19 & 3.33 & 0.4 & 0.040 & 40 & 235 & 1.60 & 776.16 & 659.74 & 20.33 & 28.80 & 64.80 & 3.19 \\
STHCC20 & 3.33 & 0.4 & 0.048 & 40 & 235 & 1.92 & 1030.00 & 875.50 & 25.63 & 18.00 & 68.43 & 2.67 \\
STHCC21 & 3.33 & 0.4 & 0.031 & 40 & 235 & 2.40 & 1230.03 & 1045.53 & 14.00 & 24.00 & 45.00 & 3.21 \\
STHCC22 & 3.33 & 0.4 & 0.034 & 40 & 235 & 2.72 & 714.09 & 606.97 & 9.00 & 21.00 & 40.00 & 4.44 \\
\hline STHP
\end{tabular}

Note. $P_{y}$ denotes the yield load, $\Delta_{y}$ is the yield displacement corresponding to $P_{y}, \Delta_{m}$ denotes the peak displacement, $P_{u}$ is the ultimate load, and $\Delta_{u}$ refers to the ultimate displacement corresponding to $P_{\mathrm{u}}$.

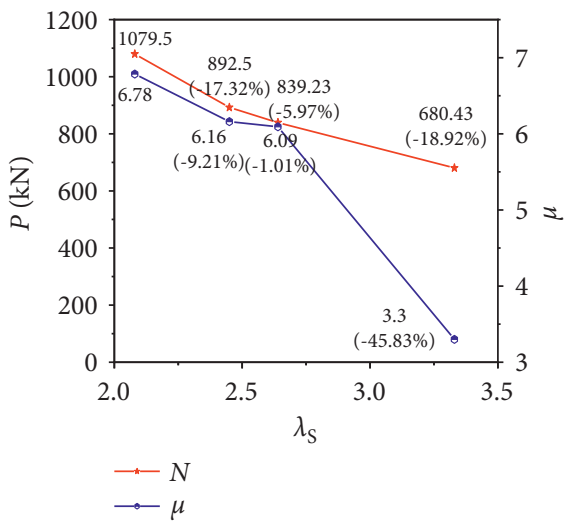

Figure 15: Relationships between $P u, \mu$, and $\lambda_{s}$. 


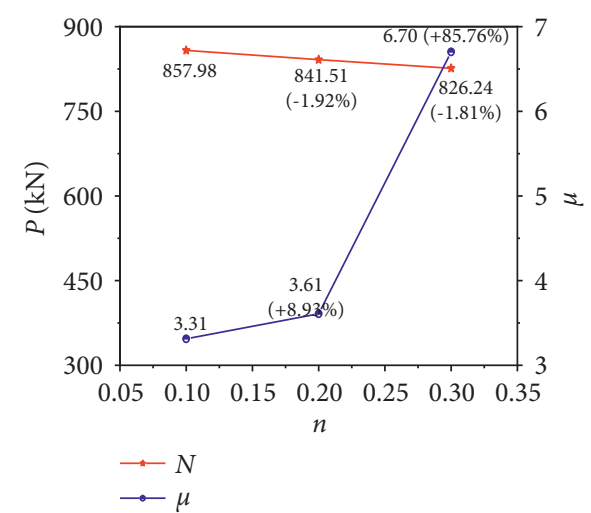

Figure 16: Relationships between $P_{u}, \mu$, and $n$.

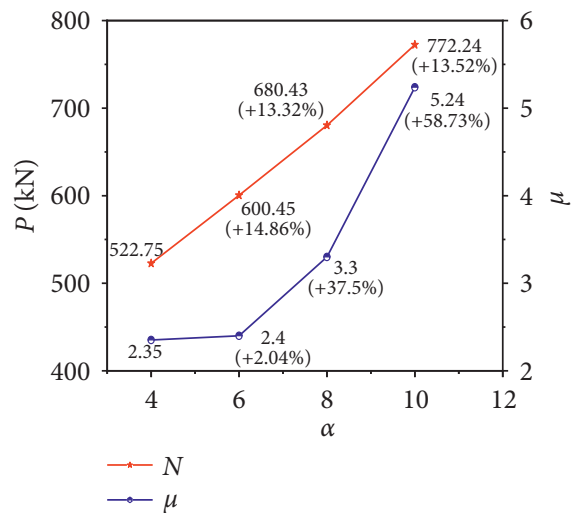

Figure 17: Relationships between $P_{u}, \mu$, and $\alpha$.

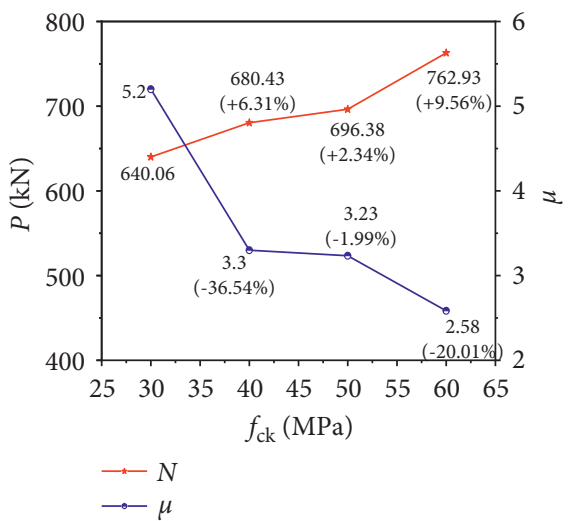

FIGURE 18: Relationships between $P_{u}, \mu$, and $f_{\text {ck }}$.

With the further increase of $n(n>0.7)$ [12], $\mu$ of the STHCCs decreases obviously, so the limit value of $n$ should be reasonably considered, which ensures that the STHCCs have good ductility $[25,30,31]$.

6.5.4. Steel Ratio of Section. The relationships between $P_{u}, \mu$, and $\alpha$ of the STHCCs are illustrated in Figure 17. It can be seen from Figure 17 that when $\alpha$ increases from 4 to 6,8 , and $10, P_{u}$ of the STHCCs increases by $14.86 \%, 13.32 \%$, and
$13.52 \%$, respectively, while $\mu$ increases by $2.04 \%, 37.5 \%$, and $58.73 \%$, respectively, which indicates that the influence of $\alpha$ on the ductility of the STHCCs is significant.

6.5.5. The Compressive Strength of Concrete. Figure 18 shows the relationships between $P_{u}, \mu$, and $f_{\mathrm{ck}}$ of the STHCCs. When $f_{\text {ck }}$ increases from $30 \mathrm{MPa}$ to $40 \mathrm{MPa}, 50 \mathrm{MPa}$, and $60 \mathrm{MPa}, P_{\mathrm{u}}$ of STHCCs increases by $6.31 \%, 2.34 \%$, and $9.56 \%$, respectively, while $\mu$ decreases by $36.54 \%, 1.99 \%$, and $20.01 \%$, 


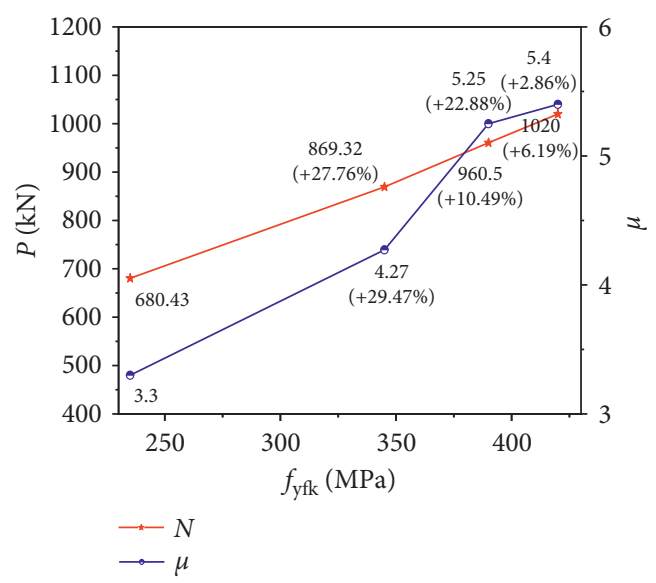

FIgURe 19: Relationships between $P_{u}, \mu$, and $f_{\mathrm{yfk}}$.

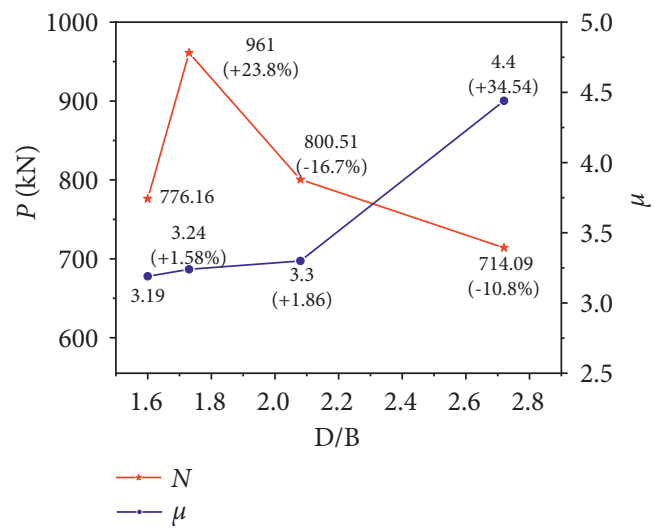

Figure 20: Relationships between $P_{u}$, $\mu$, and $D / B$.

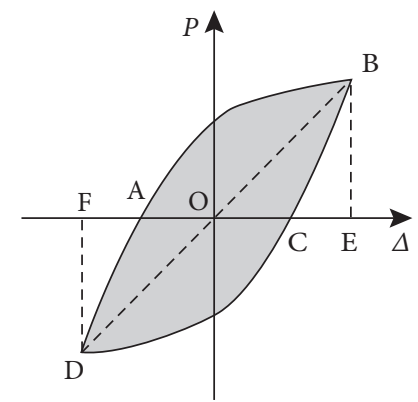

Figure 21: Calculation diagram of $E$.

respectively. With the increase of $f_{\mathrm{ck}}, P_{u}$ of the specimens increases but the ductility decreases, which indicates that the ductility of the STHCCs is significantly affected by $f_{\mathrm{ck}}$.

6.5.6. The Yield Strength of Steel Tube. The relationships between $P_{u}, \mu$, and $f_{\text {yfk }}$ of the STHCCs are shown in Figure 19. When $f_{\text {yfk }}$ increases from $235 \mathrm{MPa}$ to $345 \mathrm{MPa}$, $390 \mathrm{MPa}$, and $420 \mathrm{MPa}, P_{\mathrm{u}}$ of the STHCCs increases by $27.76 \%, 22.88 \%$, and $2.86 \%$, respectively, and $\mu$ increases by $29.47 \%, 10.49 \%$, and $6.19 \%$, respectively, which indicates that $P_{\mathrm{u}}$ and deformation capacity of the STHCCs improve with the increase of $f_{\text {yfk }}$.
6.5.7. Section Aspect Ratio. The relationships between $P_{u}, \mu$, and $D / B$ of the STHCCs are shown in Figure 20. It can be seen from Figure 20 that when $D / B$ increases from 1.6 to $1.73,2.08$, and $2.72, \mu$ of the STHCCs increases by $1.58 \%$, $1.86 \%$, and $34.54 \%$, respectively.

6.6. Energy Dissipation Capacity. The energy dissipation capacity is applied to evaluate the ability to absorb the energy released in the earthquake of the structure [9]. The energy dissipation coefficient $(E)$ is used to evaluate the energy dissipation capacity of STHCC specimens, and the energy dissipation coefficient refers to the ratio of the shadow area to the 

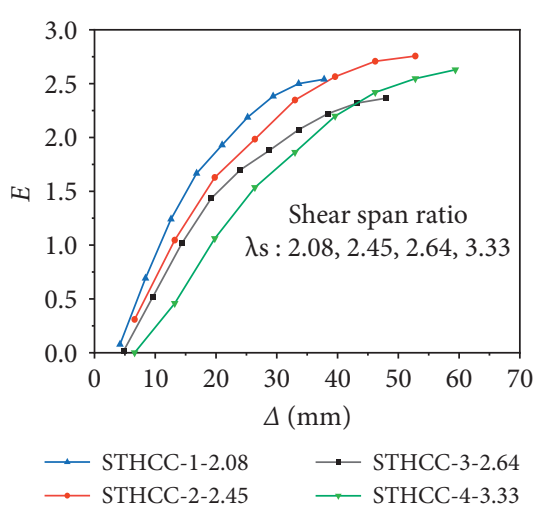

(a)

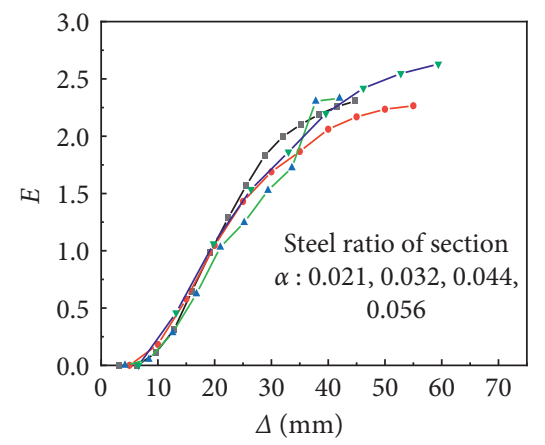

—- STHCC-12-0.032 —— STHCC-13-0.056

(d)
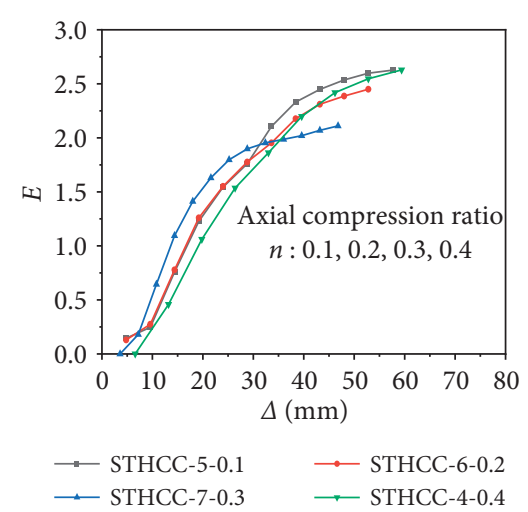

(b)

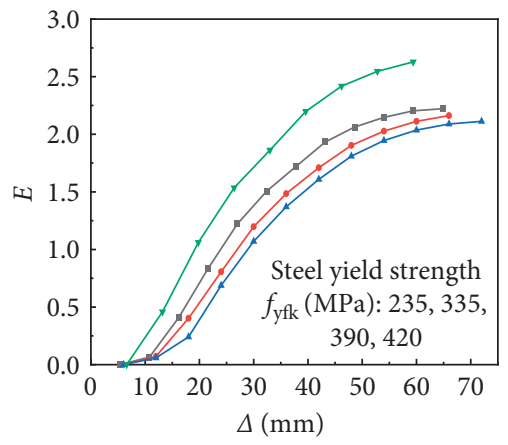

— STHCC-14-345 MPa —- STHCC-15-390 MPa — STHCC-16-420 MPa — STHCC-4-235 MPa

(e)

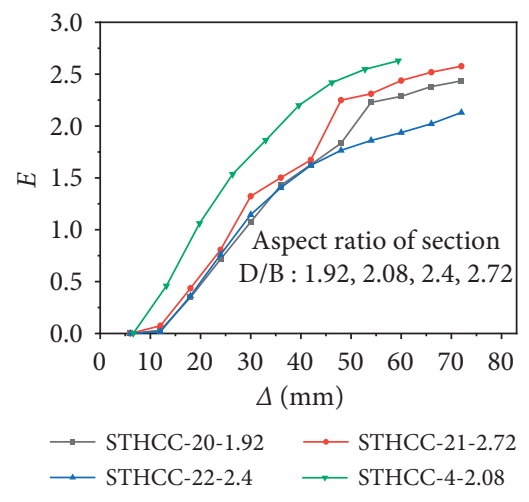

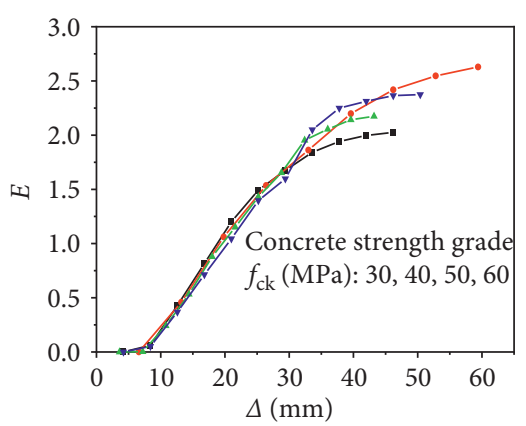

-- STHCC-8-30 MPa - - STHCC-4-40 MPa —- STHCC-9-50 MPa —- STHCC-10-60 MPa

(c)

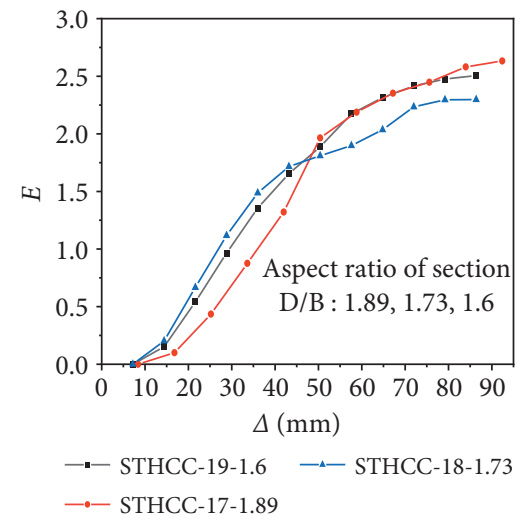

(f)

(g)

Figure 22: The relationship between $E$ and $\Delta$ for STHCCs with different parameters. (a) $\lambda_{s}: 2.08,2.45,2.64,3.33$. (b) $n: 0.1,0.2,0.3,0.4$. (c) $f_{\text {ck }}$ : $30 \mathrm{MPa}, 40 \mathrm{MPa}, 50 \mathrm{MPa}, 60 \mathrm{MPa}$. (d) $\alpha: 0.021,0.032,0.044,0.056$. (e) $f_{\mathrm{yfk}}: 235 \mathrm{MPa}, 335 \mathrm{MPa}, 390 \mathrm{MPa}, 420 \mathrm{MPa}$. (f) $D / B: 1.89,1.73,1.6$. (g) $D / B: 1.92,2.08,2.4,2.72$.

triangle DFO and the triangle BEO area, as shown in Figure 21. The energy dissipation coefficient can be calculated as follows:

$$
E=\frac{S_{(\mathrm{ABC}+\mathrm{CDA})}}{S_{(\triangle \mathrm{OBE}+\triangle \mathrm{ODF})}} .
$$

Figure 22 shows the horizontal displacement $(\Delta)$ versus the energy dissipation coefficient $(E)$ relationships of the 22 STHCCs under the first reciprocating load of each stage. It can be found from Figure 22 that the energy dissipation capacity values of the 22 STHCCs are substantially similar.

The energy dissipation capacity of STHCCs is shown in Figure 22. With the increase of $\lambda_{s}, n, f_{\mathrm{yfk}}$, and $D / B, E$ and the energy dissipation capacity of the specimens decrease gradually. It can be seen from Figures 22(c) and 22(d) that $f_{\mathrm{ck}}$ and $\alpha$ have little effect on the energy dissipation capacity of STHCCs. The existing research [32] shows that $E$ of RC 

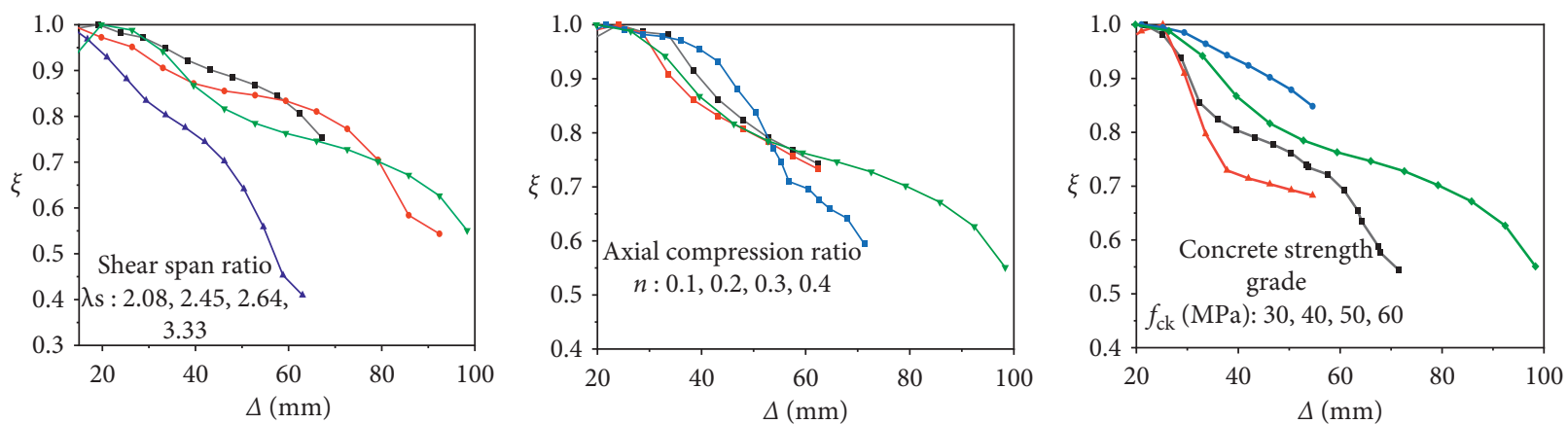

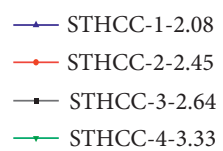

(a)

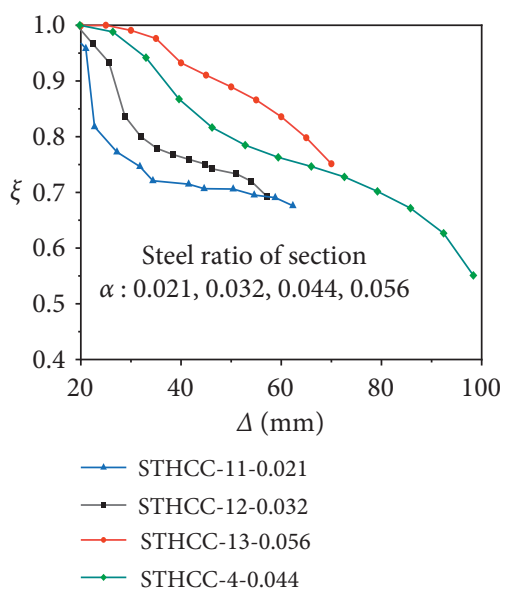

(d)

\section{- STHCC-5-0.1 \\ $\rightarrow$ STHCC-6-0.2 \\ - STHCC-7-0.3 \\ $\longrightarrow$ STHCC-4-0.4}

(b)

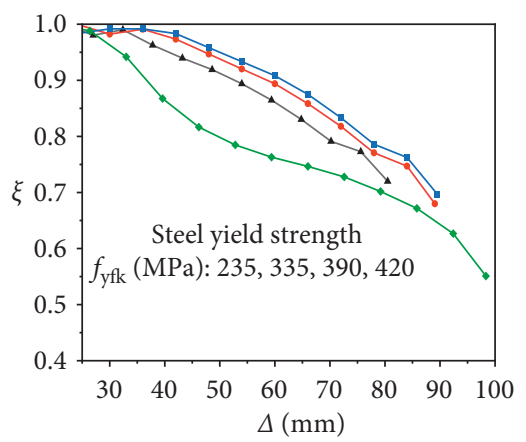

\section{- STHCC-14-345 MPa \\ - STHCC-15-390 MPa \\ $\rightarrow$ STHCC-16-420 MPa \\ $\rightarrow$ STHCC-4-235 MPa}

(e)

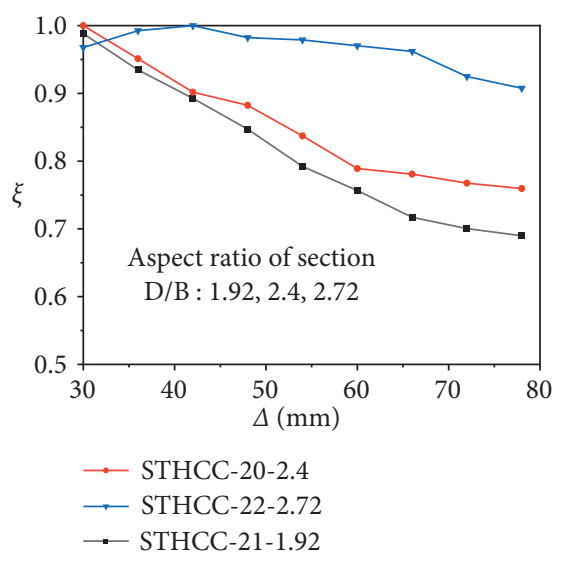

- STHCC-8-30 MPa

- STHCC-9-50 MPa

- STHCC-10-60 MPa

$\longrightarrow$ STHCC-4-40 MPa

(c)

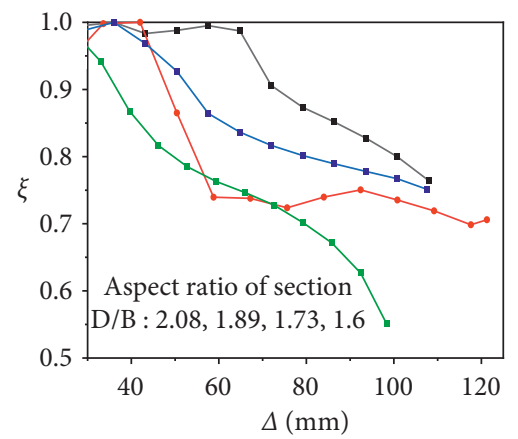

$$
\begin{aligned}
& \longrightarrow \text { STHCC-17-1.89 } \\
& \rightarrow \text { STHCC-18-1.73 } \\
& \rightarrow \text { STHCC-19-1.6 } \\
& \longrightarrow \text { STHCC-4-2.08 }
\end{aligned}
$$

(f)

(g)

FIgURE 23: The relationships between $\xi$ and $\Delta$ for STHCCs with different parameters. (a) $\lambda_{s}: 2.08,2.45,2.64,3.33$. (b) $n: 0.1,0.2,0.3,0.4$. (c) $f_{\text {ck: }}: 30 \mathrm{MPa}, 40 \mathrm{MPa}, 50 \mathrm{MPa}, 60 \mathrm{MPa}$. (d) $\alpha: 0.021,0.032,0.044,0.056$. (e) $f_{\mathrm{yfk}}: 235 \mathrm{MPa}, 335 \mathrm{MPa}, 390 \mathrm{MPa}, 420 \mathrm{MPa}$. (f) $D / B: 2.08,1.89,1.73$, 1.6. (g) $D / B: 2.4,1.92,2.72$. 


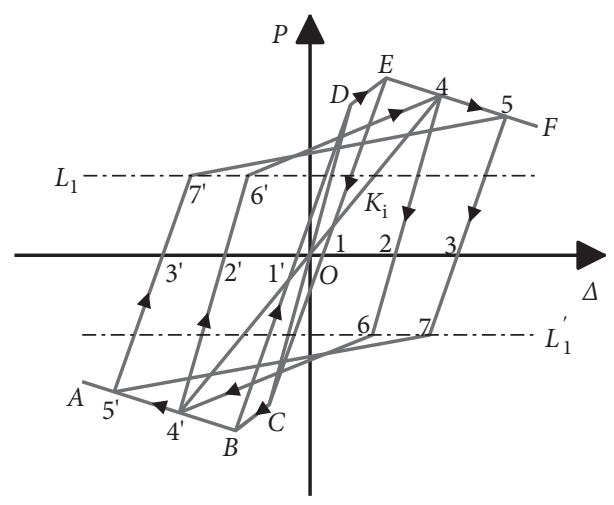

FIGURE 24: Restoring force model for STHCCs.

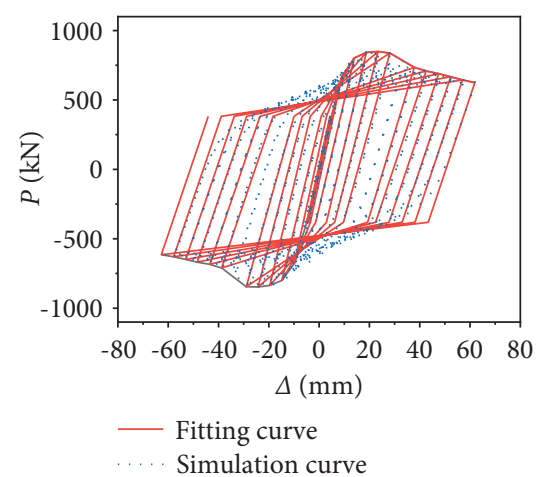

(a)

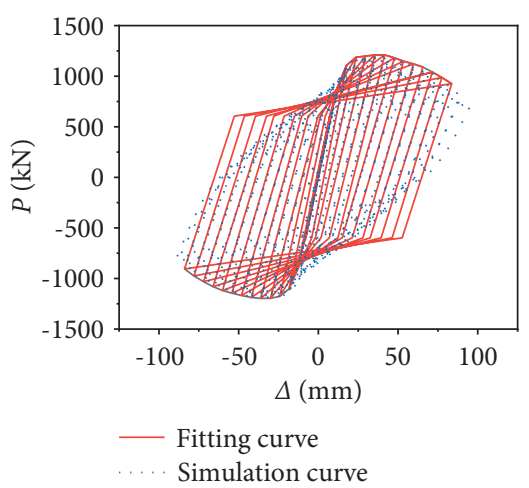

(d)

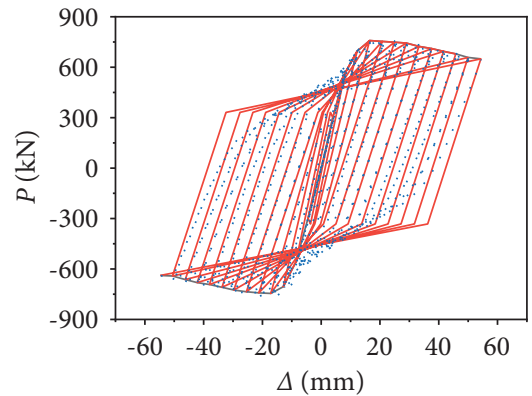

— Fitting curve

… Simulation curve

(b)

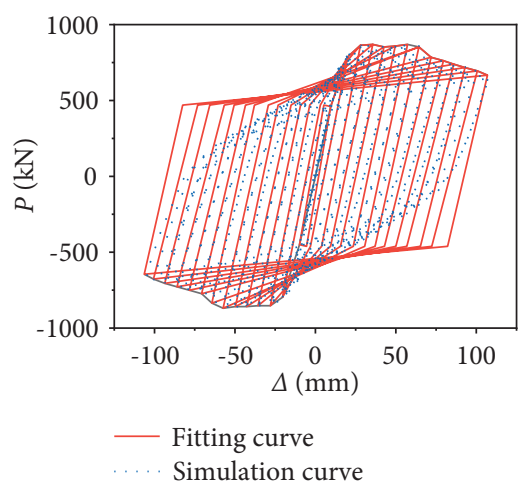

(e)

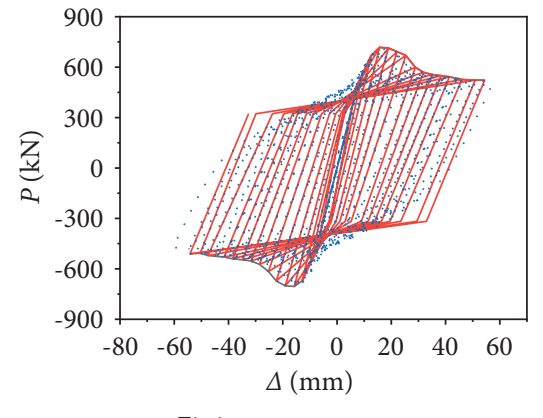

- Fitting curve Simulation curve

(c)

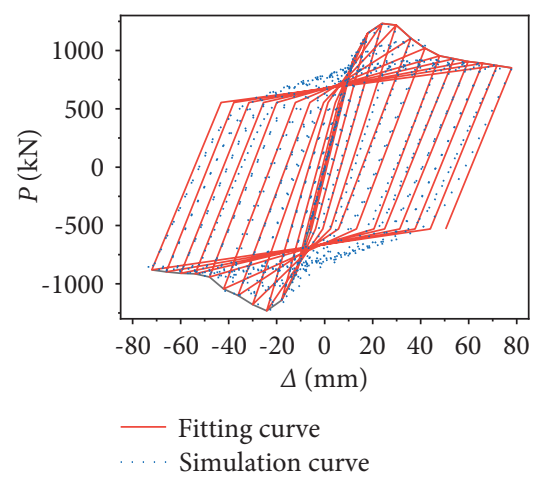

(f)

FIGURE 25: Comparisons of hysteresis curves between calculation and simulation. (a) STHCC5. (b) STHCC8. (c) STHCC12. (d) STHCC16. (e) STHCC17. (f) STHCC21.

columns is about 1.0 and $E$ of SRC columns is about 2.4; $E$ of specimens in this article can reach above 2.0 , so it is indicated that the STHCCs have excellent energy dissipation capacity.

6.7. Resistance Degradation. The resistance degradation coefficient $(\xi)$ is used to measure seismic action of STHCC specimens as shown in Figures 23(a), 23(b), 23(d), 23(e), and $23(\mathrm{~g})$. With the increase of $\lambda_{s}, n, \alpha, f_{\mathrm{yfk}}$, and $D / B, \xi$ of the STHCCs increases and the resistance degradation rate gradually slows down. Figure 23(c) shows that with the increase of $f_{\mathrm{ck}}$, the resistance degradation of the specimens gradually decreases and the resistance degradation rate accelerates. It can be concluded that within a certain range, the increase of $\lambda_{\mathrm{s}}, n, \alpha, f_{\mathrm{yfk}}$, and $D / B$ is conducive to improving the seismic performance of the structure.

6.8. Restoring Force Model. The restoring force model of STHCCs is established by statistical regression, as shown in Figure 24, in which points $D$ and $C$ represent the yield points of positive direction and negative direction. Points $E$ and $B$ represent the peak points. $\mathrm{AB}$ and $\mathrm{EF}$ represent the descent segment. The horizontal auxiliary line $\left(L_{1}\right)$ represents the 


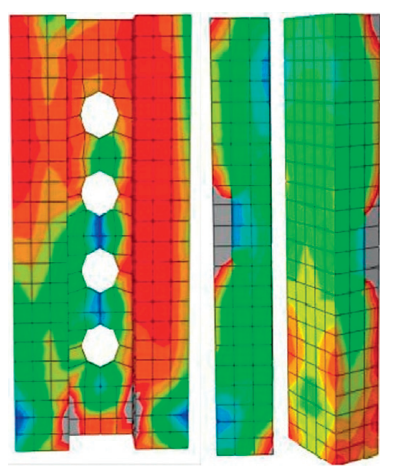

(a)

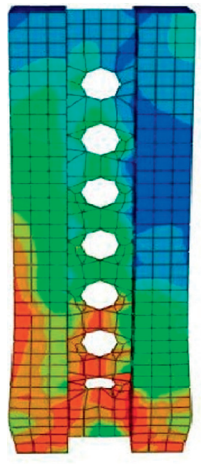

(e)
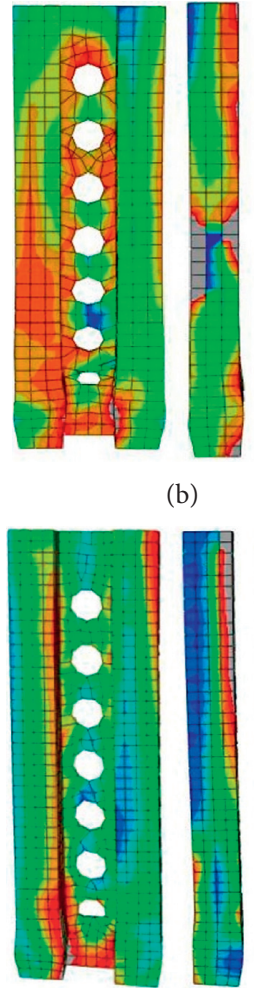

(b)
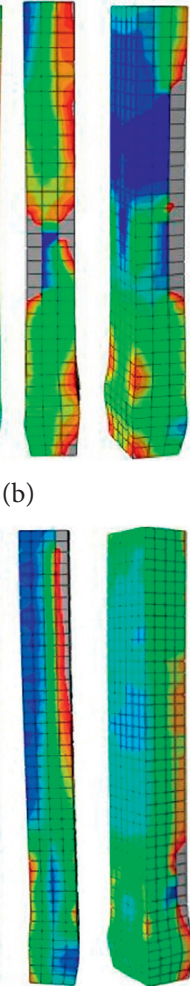

(f)

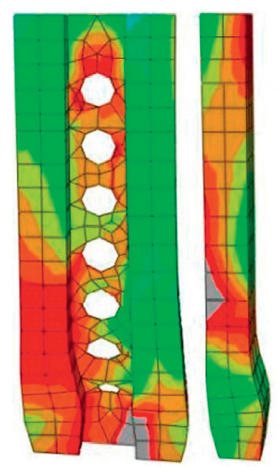

(c)
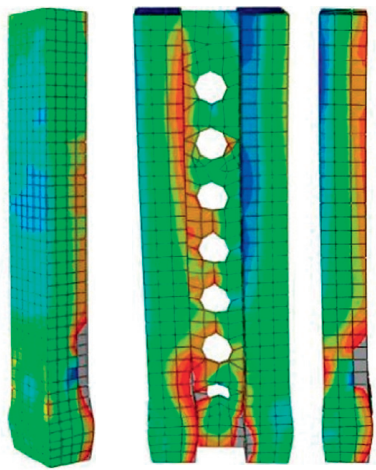

(g)
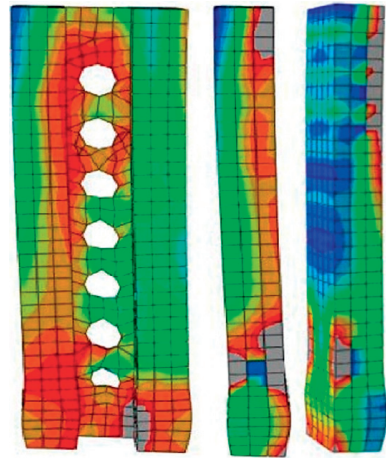

(d)
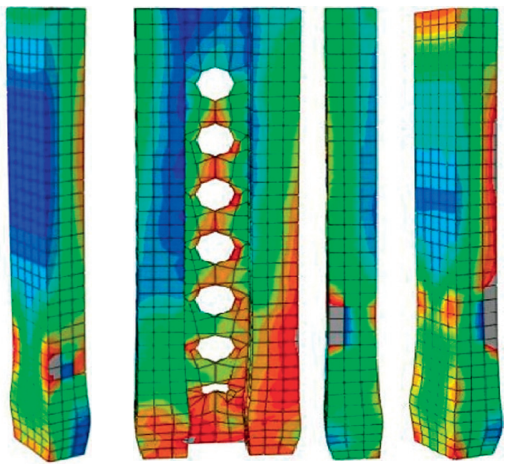

(h)

FIGURE 26: Failure modes of STHCCs. (a) STHCC2. (b) STHCC4. (c) STHCC6. (d) STHCC10. (e) STHCC13. (f) STHCC14. (g) STHCC19. (h) STHCC22.

straight line $\left(P=0.45 P_{E}\right)[13]$, and $L_{1}^{\prime}$ represents the symmetric line of $L_{1}$ about horizontal coordinate axis.

The specimens are approximately at the elastic stage before yielding, and the paths of loading and unloading process are along the elastic stage of the skeleton curves; more specifically, the OD section is loaded forward, and the OC section is loaded backward after specimens unloading to the $\mathrm{O}$ point. It can be found that the loading stiffness and unloading stiffness are both the elastic stiffness of the skeleton curves.

After the specimens yielded, the loading path develops along the skeleton curves. Before reaching the peak load, the unloading and reverse loading are carried out according to the path of point $E$ to the negative yield point $C$ and then develop along the path of point $\mathrm{C}$ to point $\mathrm{B}$. The overall loading path is D-E-1-C-B-1'-D.

After the peak load, the loading path develops along the skeleton curve from point $E$ to point 4 (point 5). The unloading path is from point 4 (point 5 ) to point 2 (point 3 ), the reverse loading path is from point 2 (point 3 ) to point $4^{\prime}$ (point $5^{\prime}$ ), the reverse unloading path is from point $4^{\prime}$ (point $5^{\prime}$ ) to point $2^{\prime}$ (point $3^{\prime}$ ), and then the forward load is loaded to the path of the skeleton curve. The overall loading path is 4

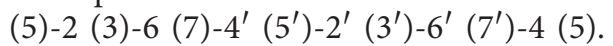

6.9. Comparisons between Restoring Force Model and Simulation Results. The hysteretic curves of STHCCs calculated by the restoring force model are shown in Figure 25. By comparing them with the simulation results, we can see that both are in good agreement; therefore, the restoring force model is feasible.

6.10. Destruction Form. The failure modes of STHCCs subjected to low cyclic loading are substantially the same, as shown in Figure 26. The column foot of the double-limb steel tube flange shows obvious outward expansion deformation. Due to the effect of axial force and horizontal force, the honeycomb steel web produces vertical compression deformation and transverse in-plane buckling deformation. The core concrete of the two-limb flange generates vertical compression deformation and bulging deformation of the upper column foot. The maximum stress of the steel tube appears in the inner side of the column foot, and the maximum bulging deformation is concentrated in the upper part of the column foot. The maximum stress of concrete occurs at the column foot and the outer side of the concrete columns. Therefore, it can be concluded that the steel tube exhibits confinement effect on the core concrete, which can effectively improves the strength of concrete and inhibits the damage of concrete. The honeycomb steel web also has a certain support for the CFST inside the flange, which can enhance the constraint effect of the inner steel tube on the concrete, the strength of the concrete, and the bearing capacity of the CFST flange. The core concrete in the steel tube effectively inhibits and delays buckling failure of the steel 
tube and improves the deformation capacity and hysteretic behavior of the STHCCs.

\section{Conclusions}

Based on the simplified constitutive model of steel and the nonlinear constitutive model of concrete, 14 STHCCs are numerically simulated by ABAQUS software. By comparison, the maximum error between the simulation and test results is $5.58 \%$, which can verify the rationality of the $\mathrm{FE}$ modeling method.

The hysteresis curves of all the specimens show full shuttle shape and strong energy dissipation capacity. $\alpha$ has a great influence on the hysteresis curves of STHCCs; with the increase of $\alpha$, the ultimate displacement of the specimens gradually increases. After reaching the peak load, the decrease of the bearing capacity of the specimens gradually slows down, and the ductility becomes better. When $n<0.4$ and $f_{\mathrm{ck}}<60 \mathrm{MPa}$, the effects of $n$ and $f_{\mathrm{ck}}$ on the bearing capacity of specimens are not remarkable. With the increase of $\alpha$ and $f_{\mathrm{yfk}}$, the bearing capacity and deformation capacity increase obviously. The stiffness degradation rate of specimens gradually slows down, and the E gradually decreases by increasing $\lambda_{s}, \alpha$, and $f_{\text {yfk }}$, but the energy dissipation capacity is still higher than that of ordinary concrete columns. With the increase of $\lambda_{s}, \alpha, f_{\mathrm{yfk}}$, and $D / B$, the resistance degradation increases; the degradation rate decreases; and $n, \alpha$, and $f_{\mathrm{ck}}$ have great influence on the ductility of specimens.

Based on the hysteresis curves obtained by the quasistatic analysis, the trilinear skeleton curve model and the restoring force model are established, and the hysteresis rules are proposed correspondingly.

By observing the failure mode of STHCCs, the steel tube has significant constraint on the core concrete and improves the compressive strength of concrete effectively. The honeycomb steel web provides effective support for the rectangular CFST flanges, and the core concrete delays the buckling failure of the steel tube validly, which can reflect the good overall hysteretic behavior of the STHCCs.

\section{Data Availability}

The data used to support the findings of this study are included within the article.

\section{Conflicts of Interest}

The authors declare that they have no conflicts of interest.

\section{Acknowledgments}

The authors are grateful for the financial support received from the Natural Science Foundation of Heilongjiang Province, grant no. LH2020E018; Scientific Research Fund of Institute of Engineering Mechanics, China Earthquake Administration, grant no. 2020D07; Opening Fund for Key Laboratory of the Ministry of Education for Structural Disaster and Control of Harbin Institute of Technology, grant no. HITCE201908; 2021 Social Science Development Research Project of Hebei Province, grant no. 20210301135;
Humanities and Social Science Research Project of Higher Education Institutions of Hebei Province, grant no. SQ2021115; General Research Project of Heilongjiang Higher Education Teaching Reform, grant no. SJGY20190096; and Northeast Petroleum University Guided Innovation Fund, grant no. 2020YDL-02.

\section{References}

[1] K. Sakino, H. Nakahara, S. Morino, and I. Nishiyama, "Behavior of centrally loaded concrete-filled steel-tube short columns," Journal of Structural Engineering, vol. 130, no. 2, pp. 180-188, 2004.

[2] Y. Essopjee and M. Dundu, "Performance of concrete-filled double-skin circular tubes in compression," Composite Structures, vol. 133, pp. 1276-1283, 2015.

[3] B. Anupriya, B. K. Jagadeesa, and R. Baskar, "Experimental investigation of shear strength of castellated beam with and without stiffeners," Journal of Structural Engineering, vol. 42, no. 4, pp. 358-362, 2015.

[4] J. Ji, Z. C. Xu, L. Q. Jiang et al., "Nonlinear buckling analysis of H-type honeycombed composite column with rectangular concrete-filled steel tube flanges," Building Structure, vol. 48, no. 15, pp. 50-55+70, 2018.

[5] J. Ji, Z. C. Xu, L. Q. Jiang, Y. C. Liu, D. Y. Yu, and M. M. Yang, "Experimental study on compression behavior of $\mathrm{H}$-shaped composite short column with rectangular CFST flanges and honeycombed steel web subjected to axial load," Journal of Building Structures, vol. 40, no. 9, pp. 63-73, 2019.

[6] J. Ji, L. Jiang, L. Q. Jiang, Y. F. Zhang, Z. C. Teng, and Y. C. Liu, "Mechanic behavior of $\mathrm{H}$ - type honeycomb composite columns with rectangular concrete-filled steel tubes subjected to eccentric load," Journal of Northeast Petroleum University, vol. 44, no. 4, pp. 121-132, 2020.

[7] A. H. Varma, J. M. Ricles, R. Sause, and L. W. Lu, "Seismic behavior and modeling of high-strength composite concretefilled steel tube (CFT) beam-columns," Journal of Constructional Steel Research, vol. 58, no. 5, pp. 725-758, 2002.

[8] P. Gajalakshmi and H. J. Helena, "Behaviour of concrete-filled steel columns subjected to lateral cyclic loading," Journal of Constructional Steel Research, vol. 75, pp. 55-63, 2012.

[9] Z. Chen, C. Jing, J. Xu, and X. Zhang, "Seismic performance of recycled concrete-filled square steel tube columns," Earthquake Engineering and Engineering Vibration, vol. 16, no. 1, pp. 119-130, 2017.

[10] Y.-C. Tang, L.-J. Li, W.-X. Feng, F. Liu, and B. Liao, "Seismic performance of recycled aggregate concrete-filled steel tube columns," Journal of Constructional Steel Research, vol. 133, pp. 112-124, 2017.

[11] J. Wang, Q. Sun, and J. Li, "Experimental study on seismic behavior of high-strength circular concrete-filled thin-walled steel tubular columns," Engineering Structures, vol. 182, pp. 403-415, 2019.

[12] F. Yin, S. D. Xue, W. L. Cao, H. Y. Dong, and H. P. Wu, "Experimental study on seismic behavior of specially-shaped multi-cell concrete-filled steel tubular columns loaded along different directions," Journal of Building Structures, vol. 40, no. 11, pp. 150-161, 2019.

[13] Z. Q. Liu, J. Y. Xue, and Q. F. Yang, "Experimental study on restoring force of solid-web steel reinforced concrete T-shaped column," Journal of Experimental Mechanics, vol. 32, no. 6, pp. 800-810, 2017.

[14] J. Ji, M. M. Yang, L. Q. Jiang, Y. C. Liu, and D. Y. Yu, "Research on seismic behavior of strength-gradient composite 
columns with built-in high-strength concrete filled steel tube," Earthquake resistant engineering and Retrofitting, vol. 42, no. 6, pp. 114-122, 2020.

[15] J. B. Mander, M. J. N. Priestley, and R. Park, "Theoretical stress-strain model for confined concrete," Journal of Structural Engineering, vol. 114, no. 8, pp. 1804-1826, 1988.

[16] J. G. Teng, T. Yu, Y. L. Wong, and S. L. Dong, "Hybrid FRP-concrete-steel tubular columns: concept and behavior," Construction and Building Materials, vol. 21, no. 4, pp. 846854, 2006.

[17] L. H. Han, Z. Tao, and W. Liu, "Concrete filled steel tubular Structures: Theory and practice," Journal of Fuzhou University (Natural Science), vol. 29, no. 6, pp. 24-34, 2001.

[18] M. Pagoulatou, T. Sheehan, X. H. Dai, and D. Lam, "Finite element analysis on the capacity of circular concrete-filled double-skin steel tubular (CFDST) stub columns," Engineering Structures, vol. 72, pp. 102-112, 2014.

[19] Gb 50010-2010, National Standard of the People's Republic of China Code for Design of Concrete Structures GB50010-2010, China Architecture \& Building Press, Beijing, China, 2010.

[20] X. L. Cao, L. M. Wu, and Z. M. Li, "Behaviour of steelreinforced concrete columns under combined torsion based on ABAQUS FEA," Engineering Structures, vol. 209, Article ID 109980, 2020.

[21] W. Liu, "Research on mechanism of concrete-filled steel tubes subjected to local compression," Doctor dissertation, Fuzhou University, Fuzhou, China, 2005.

[22] X. Dai and D. Lam, "Numerical modelling of the axial compressive behaviour of short concrete-filled elliptical steel columns," Journal of Constructional Steel Research, vol. 66, no. 7, pp. 931-942, 2010.

[23] J. R. Qian and H. Z. Kang, "Experimental study on seismic behavior of high-strength concrete-filled steel tube composite columns," Journal of Building Structures, vol. 30, no. 4, pp. 85-93, 2010.

[24] J. Xue, X. Zhang, R. Ren, L. Zhai, and L. Ma, "Experimental and numerical study on seismic performance of steel reinforced recycled concrete frame structure under low-cyclic reversed loading," Advances in Structural Engineering, vol. 21, no. 12, pp. 1895-1910, 2018.

[25] Z. X. Guo, Z. W. Zhang, Q. X. Huang, and Y. Liu, "Experimental study on hysteretic model of SRC columns," Earthquake Engineering and Engineering Vibration, vol. 29, no. 5, pp. 79-85, 2009.

[26] G. J. Zhang, X. L. Lu, and B. Q. Liu, "Study on resilience models of high-strength concrete frame columns," Engineering Mechanics, vol. 24, no. 3, pp. 83-91, 2007.

[27] J. W. Zhang, W. B. Zheng, W. L. Cao, and M. Wang, "Seismic performance of composite walls with concrete-filled square steel-tube boundary element," European Journal of Environmental and Civil Engineering, vol. 25, no. 2, pp. 1-19, 2019.

[28] H. Cai, L. H. Xu, Y. Chi, Y. X. Yan, C. L. Yu, and C. L. He, "Seismic performance of rectangular ultra-high performance concrete filled steel tube (UHPCFST) columns," Composite Structures, vol. 259, Article ID 113242, 2020.

[29] Z. W. Cai, F. C. Liu, J. T. Yu, K. Q. Yu, and L. K. Tian, "Development of ultra-high ductility engineered cementitious composites as a novel and resilient fireproof coating," Construction and Building Materials, vol. 288, Article ID 123090, 2021.

[30] X. G. Chen, Z. G. Mu, J. B. Zhang, C. K. Wang, C. H. Chen, and H. Z. Sun, "Experimental study on the seismic behavior of steel reinforced concrete columns," Journal of University of
Science and Technology Beijing, vol. 31, no. 12, pp. 1516-1524, 2009.

[31] Q. W. Wang, Q. X. Shi, W. S. Jiang, X. H. Zhang, W. Hou, and Y. Tian, "Experimental study on seismic behavior of steel reinforced concrete columns with new-type cross sections," Journal of Building Structures, vol. 34, no. 11, pp. 123-129, 2013.

[32] Q. F. Wang, J. K. Zheng, B. Zhou, Y. Y. Xu, and L. Y. Wang, "Study on seismic behavior of HRBF500 RC column based on hysteretic energy," China Civil Engineering Journal, vol. 46, no. 11, pp. 22-28, 2013. 